\title{
Experimental investigation of bond behaviour of two common GFRP bar types in high - strength concrete
}

\author{
Najia Saleh, Ashraf Ashour, Dennis Lam and Therese Sheehan \\ School of Engineering, University of Bradford, Bradford, BD7 1DP, UK \\ E-mails: N.saleh1@student.bradford.ac.uk, a.f.ashour@bradford.ac.uk, \\ d.lam1@bradford.ac.uk, T.sheehan@bradford.ac.uk
}

\section{ABSTRACT}

Although several research studies have been conducted on investigating the bond stress -slip behaviour of Glass-Fibre Reinforced Polymer (GFRP) bars embedded in high strength concrete (HSC) using a pull-out method, there is no published work on the bond behaviour of GFRP bars embedded in high strength concrete using a hinged beam. This paper presents the experimental work consisted of testing 28 hinged beams prepared according to RILEM specifications. The investigation of bond performance of GFRP bars in HSC was carried out by analysing the effect of the following parameters: bar diameter (9.5, 12.7 and $15.9 \mathrm{~mm}$ ), embedment length (5 and 10 times bar diameter), surface configuration (helical wrapping with slight sand coating (HW-SC) and sand coating (SC)) and bar location (top and bottom). Four hinged beams reinforced with $16 \mathrm{~mm}$ steel bar were also tested for comparison purposes.

The majority of beam specimens failed by pull-out. Visual inspection of the test specimens showed that the bond failure of GFRP (HW-SC) bars usually occurred owing to the bar surface damage, while the bond failure of GFRP (SC) bars was caused due to the detachment of sand coating. The GFRP bars with helical wrapping and sand coated surface configurations showed different bond behaviour and it was found that the bond performance of the sand coated surface was better than that of the helically wrapped surface. Bond strength reduced as the embedment length and bar diameter increased. It 
was also observed that the bond strength for the bottom bars was higher than that of the

30 top bars. The bond strength was compared against the prediction methods given in $\mathrm{ACl}-$

$31440.1 \mathrm{R}, \mathrm{CSA}-\mathrm{S} 806$ and CSA-S6 codes. All design guidelines underestimated the bond

32 strength of both GFRP re-bars embedded in high strength concrete.

33 Keywords: GFRP bar, high strength concrete, hinged beam, bond behaviour and design

34 code

\section{Introduction}

36 In the last decades, fibre reinforced polymer (FRP) re-bars have been used as an

37 alternative to the conventional steel reinforcement in concrete structures to overcome the

38 corrosion problem effectively. FRP bars have high corrosion resistance, high tensile

39 strength, light weight and speed of application leading to decreasing construction costs.

40 However, FRP composites suffer from lack of ductility, lower bond strength, lower elastic

41 modulus and higher cost than steel. The bond mechanism between FRP re-bars and

42 concrete is a critical design parameter that controls the performance of reinforced

43 concrete members at serviceability and ultimate limit states. Therefore, several research

44 investigations have taken place to investigate the bond properties of FRP re-bars

45 embedded in concrete.

46 Most previous studies investigated the bond behaviour of FRP re-bars in concrete using

47 pull-out test method [1-6]. However, very limited experimental data are available in the

48 literature regarding bond behaviour of FRP re-bars in concrete using hinged beams [7-

49 10], as they are more challenging to prepare and test. Despite this, hinged beams are

50 more realistic and representative of stress conditions in $\mathrm{RC}$ members in bending than pull-

51 out specimens. Benmokrane et al. [7] tested twelve beams reinforced with helically 
52 wrapped GFRP and steel bars in normal strength concrete (NSC). It was found that the

53 bond strengths of GFRP re-bars varied from 6.4 to $10.6 \mathrm{MPa}$, depending on bar diameter.

54 In addition, the bond strength of GFRP bars was lower (60 to $90 \%$ ) than that of steel bars,

55 also depending on bar diameter. It was concluded that as bar diameter increases, bond 56 strength reduces. Tighiouart et al. [8] investigated 64 beams reinforced with GFRP bars

57 having two outer surfaces (spirally wound and deformed), and steel bars. It was reported

58 that the average bond strength was in the range of 5.1 to $12.3 \mathrm{MPa}$, depending on bar

59 diameter and embedment length. Also, GFRP bars showed bond strength values lower

60 than steel bars. Xue et al. [10] examined 30 unconfined hinged beams reinforced with

61 sand-coated deformed GFRP and steel bars. Experimental results showed that

62 specimens with embedment lengths less than $5 \mathrm{~d}$ b, failed by pull-out, while those with

63 embedment lengths greater than $5 \mathrm{~d}$ b, failed by splitting. Both types of failure were

64 observed in specimens with bonded lengths equal to $5 \mathrm{~d}$. It was found that the increase

65 of bar diameter and embedment length resulted in decreasing the bond strength.

66 In recent years, a marked increase in the use of high-strength concrete (HSC) has been

67 evident in construction projects around the world. HSC offers significantly better structural 68 engineering properties, namely better durability, higher compressive and tensile 69 strengths, higher stiffness compared with conventional normal-strength concrete. The 70 previous studies have focused on investigating the bond behaviour of glass fibre71 reinforced polymer (GFRP) bars in normal strength concrete (NSC) [7, 8]. However, no 72 investigation was conducted on high strength concrete hinged beams reinforced with 73 GFRP-SC and GFRP (HW-SC) bars.

74 Several GFRP bars have been manufactured with various surface configurations (ribbed, 75 helical wrapped, indented and sand coated). However, there is no standardization for 
76 surface characteristics, unlike steel bars. Subsequently, the determination of bond

77 properties of each surface is a fundamental requirement for the structural use, because

78 this influences the mechanism of load transfer from concrete to reinforcing bar. Very

79 limited studies were done to investigate the effect of bar surface on bond strength using

80 a hinged beam method. The results obtained by Tighiouart et al. [8] indicated that the ratio

81 of the bond strength for a GFRP deformed surface to that of a GFRP spirally wound

82 surface changed from 1.15 to 1.48 depending on bar diameter. Mazaheripour et al. [11]

83 found that the bond strength of the ribbed GFRP bars is higher than that of the sand-

84 coated GFRP bars embedded in self-compacting steel fibre reinforced concrete.

85 Therefore, this study aimed to examine and compare the bond behaviour of two common

86 GFRP bar types (helical wrapping with slightly sand coating and sand coating).

87 The literature illustrates that the FRP bar position effect on bond strength was investigated

by some authors [8, 12-16]. Tighiouart et al. [8] used the pull-out test to examine the

89 position effect of GFRP (spirally wound) bar in NSC on bond strength. The results showed

that the ratio of the bond strengths of the bottom bars to the top bars was in the range

91 between 1.09 and 1.32 with an average of 1.29 . In addition, the ratios obtained from the

92 results of pull-out test changed from 1.08 to 1.38 with an average of 1.23 and from 1.11

93 to 1.22 with an average of 1.18 for NSC and HSC, respectively [12]. Moreover, Ehsani et

94 al. [13] reported that the top modification factor was 1.25 from testing pull-out specimens.

95 Furthermore, Benmokrane and Masmoudi [14] obtained the top modification factor of FRP

96 C-bar equal to 1.1 from pull-out test. The results obtained from testing pull-out specimens

97 revealed that the reduction of water to cement ratio and using high cementitious materials

98 decreased the bond strength variation between the upper and lower zones of the 99 specimens [16]. While, Pay et al. [15] investigated the bar position effect on bond 
behaviour using lap splice specimens. The results reported that the bond strength of the

101 top-cast specimens is slightly lower (average 7\% reduction) than that of the bottom-cast 102 specimens due to lesser water bleeding and concrete slump. However, the effect of bar 103 position on bond strength has not been investigated using hinged beam. Therefore, the 104 current study aimed to investigate the influence of bar position on bond strength. These 105 points are the main motivations to conduct this research and also providing data for 106 designers and code development.

107 Bond characteristics are influenced by many parameters, such as bar diameter, 108 embedment length, concrete strength, surface configuration, concrete cover and bar 109 position. Experimental investigations were carried out to understand the effect of these 110 factors on bond performance and empirical equations were developed to estimate the 111 bond strength of FRP bars in concrete [2, 8, 13]. However, most equations in the literature 112 included two main parameters: bar diameter and concrete strength, the effect of 113 embedment length, surface configuration, concrete cover, bar position and bar type were 114 ignored. In addition, design guidelines have proposed equations to determine the 115 development length of FRP bars in conventional concrete considering the effect of bar 116 diameter, concrete strength, concrete cover, bar position and bar surface. Canadian 117 codes $[17,18]$ acknowledge the influence of surface treatment on bond performance by 118 suggesting a bar surface factor in their equations, whereas $\mathrm{ACI} 440.1 \mathrm{R}$ code does not 119 include any special provisions for surface configurations. Moreover, the effect of bar type 120 on bond characteristics was considered in the CAN/CSA-S806 equation only. All codes 121 neglected the influence of transverse reinforcement, except CAN/CSA-S6. The 122 performance of these design equations should be investigated to validate their 
123 applicability to high strength concrete reinforced with GFRP (HW-SC) and GFRP (SC) re124 bars.

125 This paper presents the experimental testing of twenty-four GFRP and four steel 126 reinforced concrete hinged beams. The aim of this study is to gain a better understanding 127 of the bond behaviour between GFRP bars and concrete. The bond behaviour is analyzed

128 for GFRP bars with two different surfaces showing the effect of bar diameter, embedment 129 length, surface configuration and bar position on bond strength. In addition, this research 130 aims to validate code equations in the case of high strength concrete.

\section{Experimental investigation}

\section{$132 \quad 2.1 \quad$ Materials}

133 Hinged beams were constructed using ready - mixed concrete with the maximum 134 aggregate size of $10 \mathrm{~mm}$. Cylinder $(150 \times 300 \mathrm{~mm})$ and cube $(100 \times 100 \times 100 \mathrm{~mm})$ 135 specimens were cast and cured under the same condition as the test beams. Cylinders 136 and cubes were tested immediately after testing hinged beams to provide the splitting 137 tensile and cube compressive strengths of concrete. GFRP (HW-SC), GFRP (SC) and 138 steel bars were used in this study. The sand coated GFRP and helically wrapped with 139 slightly sand coated GFRP re-bars shown in Figure 1 were made of continuous 140 longitudinal fibres impregnated in vinylester resin: the minimum content of continuous 141 ECR-glass fibres was $75 \%$ (per weight) and the maximum content of vinylester resin was $14225 \%$, and the content of continuous E-glass fibres $80 \%$ (per weight) and vinylester resin $14320 \%$, respectively. The tensile strength and elastic modulus of GFRP and steel bars were 144 determined according to specifications ASTM D7205/D7205M [19] and ASTM 145 A706/A706M [20], respectively. The tensile strength of GFRP (SC) bars is higher than 146 that of GFRP (HW-SC) bars as shown in Table 1, due to the difference in the 
148 GFRP bars would not have a major effect on their bond characteristics with concrete but would have on their development length. The tensile force The actual diameters were 150 measured according to $\mathrm{ACl} 440.3 \mathrm{R}-12$ [21]. The geometrical and mechanical properties 151 of GFRP and steel bars are summarized in Table 1.

Table 1. Geometrical and mechanical properties of GFRP and steel bars

\begin{tabular}{c|c|c|c|c|c|c|c}
\hline Bar type & \multicolumn{3}{|c|}{ GFRP (HW-SC) } & \multicolumn{3}{c|}{ GFRP $(\mathrm{SC})$} & Steel \\
\hline Bar size & $3 \#$ & $4 \#$ & $5 \#$ & $3 \#$ & $4 \#$ & $5 \#$ & $5 \#$ \\
\hline $\begin{array}{c}\text { Nominal diameter } \\
(\mathrm{mm})\end{array}$ & 9.5 & 12.7 & 15.9 & 9.5 & 12.7 & 15.9 & 16 \\
\hline $\begin{array}{c}\text { Measured diameter } \\
(\mathrm{mm})\end{array}$ & 10.76 & 13.44 & 16.76 & 10.4 & 13.33 & 16.74 & - \\
\hline $\begin{array}{c}\text { Tensile strength } \\
(\mathrm{MPa})\end{array}$ & $\begin{array}{c}827 \\
(940.2)\end{array}$ & $\begin{array}{c}758 \\
(797)\end{array}$ & $\begin{array}{c}724 \\
(867.9)\end{array}$ & $\begin{array}{c}1227.3 \\
(1224.6)\end{array}$ & $\begin{array}{c}1375 \\
(1175.4)\end{array}$ & $\begin{array}{c}1373.7 \\
(1210.3)\end{array}$ & $\begin{array}{c}672 \\
(666)\end{array}$ \\
\hline Ultimate strain (\%) & 1.79 & 1.64 & 1.57 & 2.4 & 2.7 & 2.7 & - \\
\hline $\begin{array}{c}\text { Elastic of modulus } \\
(\mathrm{GPa})\end{array}$ & $\begin{array}{c}46 \\
(51.7)\end{array}$ & $\begin{array}{c}46 \\
(49.7)\end{array}$ & $\begin{array}{c}46 \\
(46.9)\end{array}$ & $\begin{array}{c}50 \\
(50.98)\end{array}$ & $\begin{array}{c}51 \\
(51.57)\end{array}$ & $\begin{array}{c}51 \\
(52.15)\end{array}$ & $\begin{array}{c}200 \\
(199)\end{array}$ \\
\hline $\begin{array}{c}\text { Yielding strength } \\
(\mathrm{MPa})\end{array}$ & - & - & - & - & - & - & $\begin{array}{c}582 \\
(569)\end{array}$ \\
\hline
\end{tabular}
The values between brackets measured in the laboratory are the average of three samples, whereas other values are provided by the manufacturer.

(a) Helically wrapped with sand coated surface (type A)
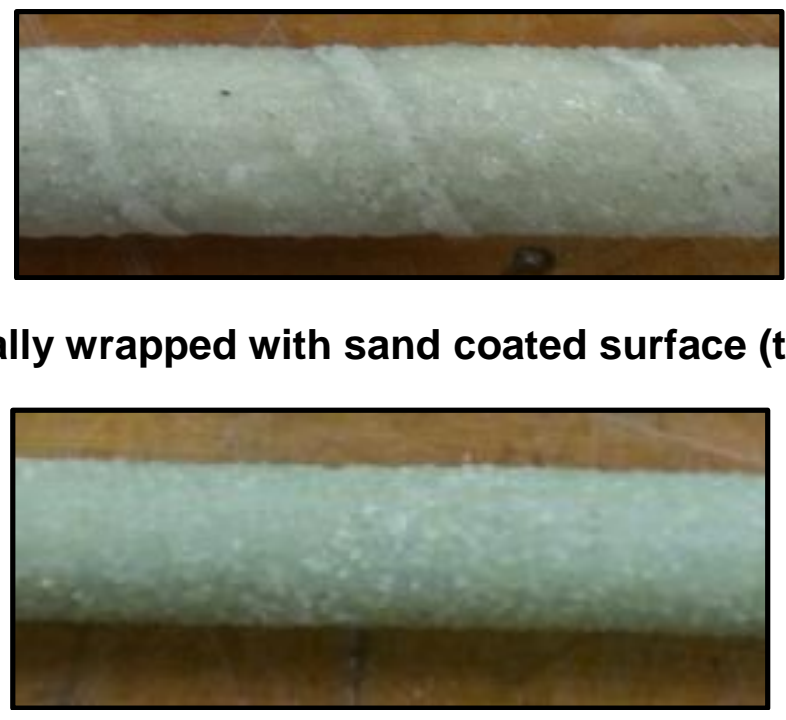

(b) Sand coated surface (type B)

Figure 1. Surface configurations of GFRP re-bars 


\section{$2.2 \quad$ Test specimens}

166 Twenty-four GFRP reinforced concrete hinged beams and four steel reinforced concrete 167 specimens were tested. The parameters investigated were bar diameter $(9.5,12.7$ and $16815.9 \mathrm{~mm}$ for GFRP and $16 \mathrm{~mm}$ for steel), embedment length (five and ten times bar diameter), bar position (bottom and top) and surface configuration (helical wrapping with

170 slightly sand coating and sand coating). The geometrical details of hinged beams are

171 given in Figure 2. The un-bonded length was covered by a plastic sleeve to prevent

172 contact between the bar and concrete. The presence of confining reinforcement did not 173 appear to influence the bond strength as reported by the ACI 440.1R code [22]. Therefore, 174 the current study has aimed to cast the hinged beams without transverse reinforcement, 175 similar to the specimens of Xue et al. [10] and Mazaheripour et al. [11]. The concrete mix 176 C1 was used to cast twelve specimens reinforced with GFRP (type A) and two steel 177 reinforced concrete hinged beams having embedment length $5 \mathrm{db}$. Specimens reinforced 178 with GFRP (type B) and those reinforced with steel bars having embedment length $10 \mathrm{~d}_{\mathrm{b}}$ 179 were cast using the second batch C2. The test specimens for each bar type were 180 classified into two series: (a) that were cast with the bottom bar position as shown in Figure 2, (b) that were cast with the top bar position as the same as presented in Figure 2, but in 182 an inverted position to make the lower part where the upper part should be. Before casting, 183 the inner sides of the wooden moulds were covered by a thin film of oil to ease demoulding 184 of specimens. The concrete was placed in two layers and each layer was vibrated by 185 using a poker vibrator. After casting, all specimens were covered with polythene sheet to 186 prevent evaporation of water from the unhardened concrete until demoulding. After two 187 weeks, the specimens were demoulded, marked, covered with polythene sheet and stored 188 in the lab temperature until testing. 


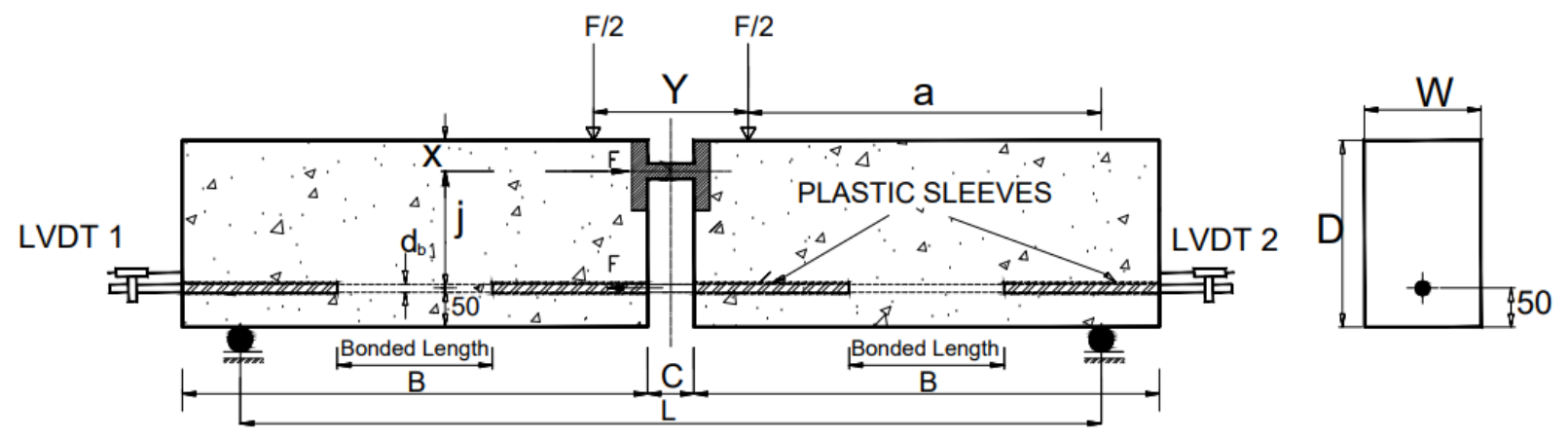

\begin{tabular}{|c|c|c|c|c|c|c|c|c|c|}
\hline Beam No. & $\mathbf{d}_{\mathbf{b}}$ & $\mathbf{W}$ & $\mathbf{D}$ & $\mathbf{L}$ & $\mathbf{B}$ & $\mathbf{C}$ & $\mathbf{X}$ & $\mathbf{Y}$ & $\mathbf{j}$ \\
\hline Type I & $10-14$ & 100 & 180 & 650 & 375 & 50 & 30 & 150 & 100 \\
\hline Type II & $16-32$ & 150 & 240 & 1100 & 600 & 60 & 40 & 200 & 150 \\
\hline
\end{tabular}

Figure 2. Hinged beam test arrangement (dimensions in $\mathrm{mm}$ )

\subsection{Experimental set-up}

The beam tests were conducted in accordance with the requirements of the RILEM specification [23]. Specimens consisted of two rectangular concrete blocks joined at the top by a steel hinge and at the bottom by a reinforcing bar to investigate its bond with concrete. The hinged beam was resting on two roller bearings and subjected to two equal forces symmetrically on either side of a ball joint using a testing machine with a capacity of $500 \mathrm{kN}$ as shown in Figure 3(a). Linear variable displacement transducers (LVDTs) were attached to the extended part of the reinforcing bar and held against the concrete end surface to measure the unloaded end slip (accurate to $\pm 0.025 \mathrm{~mm}$ ) as illustrated in Figure 3(b). Applied load and LVDT readings were automatically recorded using a data logger. All specimens were tested under displacement control mode so that the post-peak behaviour can be recorded. The loading rate was $0.02 \mathrm{~mm} / \mathrm{sec}$ and it was kept constant and continuous until complete failure. 


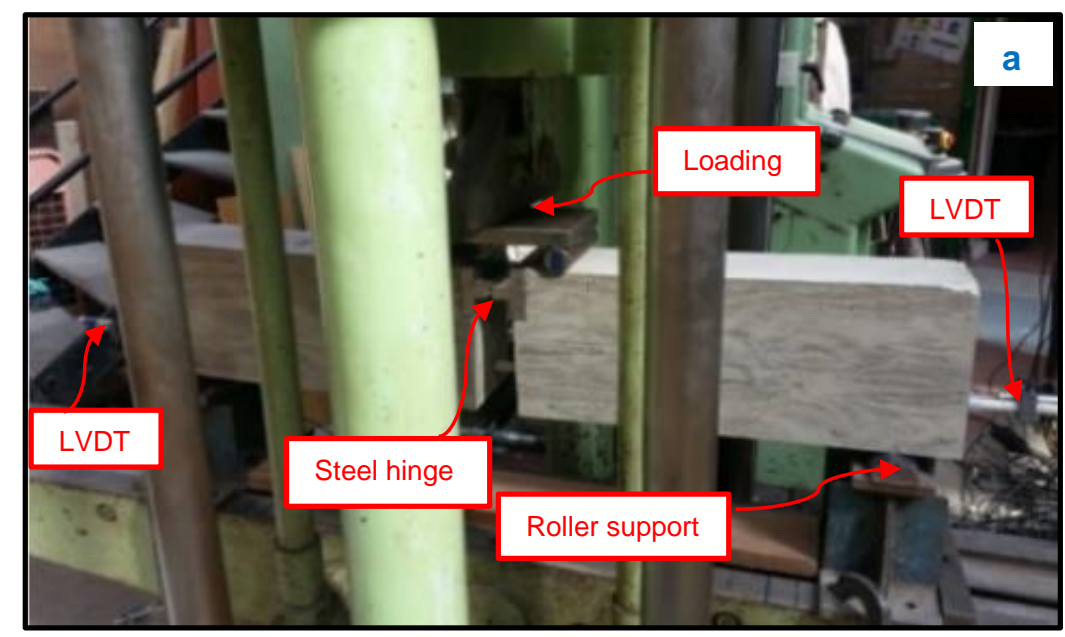

\section{Test results and discussion}

Figure 3. Hinged beam test set-up: (a) front view and (b) side view

Experimental results were used to develop the bond stress - slip relationships. The tensile load acting on the reinforcing bar can be determined by equilibrium of forces as follows:

218 For Type I specimens

$$
\begin{aligned}
& T=\frac{\frac{F}{2} \cdot a}{j}=1.25 .(\mathrm{F}) \\
& T=\frac{\frac{F}{2} \cdot a}{j}=1.50 .(\mathrm{F})
\end{aligned}
$$

220 The average bond stress could be calculated as presented in the equation below. 


$$
\tau=\frac{T}{\pi \cdot d_{b} \cdot l_{e}}
$$

222 where $\mathrm{T}$ is the tensile load in reinforcing bar $(\mathrm{N}) ; \frac{F}{2}$ is the applied load $(\mathrm{N})$; $a$ is the shear 223 span $(\mathrm{mm}) ; \mathrm{j}$ is the lever arm $(\mathrm{mm}) ; \tau$ is the bond stress (MPa); $d_{b}$ is the nominal bar 224 diameter $(\mathrm{mm})$ and $l_{e}$ is the embedment length $(\mathrm{mm})$. The maximum applied load $F_{\max }$ $225(\mathrm{kN})$, the maximum bond strength $\left(\tau_{\max }\right)$ with the corresponding free end slip $(\mathrm{S})$ are 226 presented in Tables 2 (for type A specimens) and 3 (for type B specimens). The average 227 cube compressive strength of concrete $\mathrm{C} 1$ and $\mathrm{C} 2$ obtained from testing ten cubes were $22897.38 \mathrm{MPa}$ and $81.74 \mathrm{MPa}$ at the testing day of hinged beams, respectively. While the 229 splitting tensile strength of concrete C1 and C2 obtained from testing five cylinders were $2304.13 \mathrm{MPa}$ and 3.24 MPa at the testing day of hinged beams, respectively. The definition 231 of beam notation is as follows: the first letter denotes the bar type (A for GFRP (HW-SC), 232 B for GFRP (SC) and C for steel); the first number indicates the bar diameter; the third 233 one denotes the embedment length and the last letter refers to the bar position (B for 234 bottom and T for top bar location). 
Table 2 - Bond test results of GFRP (type A) and steel bars in concrete C1

\begin{tabular}{|c|c|c|c|c|}
\hline Beam label. & $\begin{array}{c}\boldsymbol{F}_{\max } \\
\mathbf{k N}\end{array}$ & $\begin{array}{c}\boldsymbol{\tau}_{\max } \\
\mathbf{M P a}\end{array}$ & $\begin{array}{c}\mathbf{S} \\
\mathbf{m m}\end{array}$ & $\begin{array}{c}\text { Failure } \\
\text { mode }\end{array}$ \\
\hline A-9.5-5d-B & 30.56 & 26.94 & 0.536 & Pull-out \\
\hline A-9.5-5d-T & 29.43 & 25.94 & 0.609 & Pull-out \\
\hline A-12.7-5d-B & 45.39 & 22.39 & 4.426 & Pull-out \\
\hline A-12.7-5d-T & 39.95 & 19.70 & 11.91 & Pull-out \\
\hline A-15.9-5d-B & 55.09 & 20.80 & 0.213 & Pull-out \\
\hline A-15.9-5d-T & 48.02 & 18.13 & 1.176 & Pull-out \\
\hline A-9.5-10d-B & 65.49 & 28.86 & 0.642 & Pull-out \\
\hline A-9.5-10d-T & 59.43 & 26.19 & 0.418 & Pull-out \\
\hline A-12.7-10d-B & 68.91 & 16.99 & 2.33 & Pull-out \\
\hline A-12.7-10d-T & 68.18 & 16.81 & 1.80 & Pull-out \\
\hline A-15.9-10d-B & 82.35 & 15.55 & 0.119 & Pull-out /Splitting \\
\hline A-15.9-10d-T & 81.41 & 15.37 & 0.263 & Pull-out /Splitting \\
\hline C-16-5d-B & 69.92 & $>26.07$ & 0.31 & Shear \\
\hline C-16-5d-T & 64.54 & $>24.06$ & 0.21 & Shear \\
\hline
\end{tabular}

Table 3 - Bond test results of GFRP (type B) and steel bars in concrete C2

\begin{tabular}{|l|c|c|c|l|}
\hline Beam label. & $\begin{array}{c}\boldsymbol{F}_{\max } \\
\mathbf{k N}\end{array}$ & $\begin{array}{c}\boldsymbol{\tau}_{\max } \\
\mathbf{M P a}\end{array}$ & $\begin{array}{c}\mathbf{S} \\
\mathbf{m m}\end{array}$ & $\begin{array}{l}\text { Failure } \\
\text { mode }\end{array}$ \\
\hline B-9.5-5d-B & 33.72 & 29.72 & 0.141 & Pull-out \\
\hline B-9.5-5d-T & 33.20 & 29.26 & 0.11 & Pull-out \\
\hline B-12.7-5d-B & 59.78 & 29.48 & 0.115 & Pull-out \\
\hline B-12.7-5d-T & 49.30 & 24.31 & 0.316 & Pull-out \\
\hline B-15.9-5d-B & 73.21 & 27.64 & 0.104 & Pull-out \\
\hline B-15.9-5d-T & 52.22 & 19.72 & 0.12 & Pull-out \\
\hline B-9.5-10d-B & 64.33 & 28.34 & 0.096 & Pull-out \\
\hline B-9.5-10d-T & 58.46 & 25.76 & 0.1 & Pull-out \\
\hline B-12.7-10d-B & 91.11 & 22.47 & 0.231 & Pull-out \\
\hline B-12.7-10d-T & 83.94 & 20.70 & 0.073 & Pull-out \\
\hline B-15.9-10d-B & 112.1 & $>21.16$ & 0.053 & Shear \\
\hline B-15.9-10d-T & 83.27 & 15.72 & 0.07 & Pull-out \\
\hline C-16-10d-B & 109.2 & $>20.37$ & 0.173 & Yielding \\
\hline C-16-10d-T & 105.4 & $>19.65$ & 0.088 & Yielding \\
\hline
\end{tabular}




\subsection{Bond stress - slip relationship}

304 Bond stress - unloaded end slip curves for GFRP (type A) and GFRP (type B) reinforced 305 hinged beams were plotted in Figures 4 and 5, respectively. Figure 6 presents the bond 306 stress - unloaded end slip responses for steel reinforced hinged beams. In general, the bond stress - slip curves of identical specimens with differing bar position only are similar.

The bond stress - slip relationships are presented according to bar diameter, embedment length, surface characteristics, bar position and bar type to observe the influence of these main parameters on the bond behaviour in case of high strength concrete.

311 The general bond stress - slip behaviour is described by a high increase of initial bond stress without a significant slip in both GFRP types because of good chemical adhesion between the bar surface and surrounding concrete. After the chemical adhesion is 314 exhausted, bond stress continues to increase with a small slip increase until the peak point. At this stage, bearing and friction dominate to resist the pull-out load in the case of 316 specimens reinforced with GFRP (HW-SC) bars, whereas for the GFRP (SC) reinforced hinged beams, only friction resistance controls the response. The post - peak bond stress 318 of the GFRP (type A) reinforced specimens that failed by pull-out only decayed gradually with increasing free end slip in a controlled ductile way. For hinged beams having 12.7

$320 \mathrm{~mm}$ bar diameter with embedment length $10 \mathrm{db}$, their bond stress dropped suddenly with

321 a sharp slip due to shear cracks subsequent to the pull-out failure. Also, the same 322 softening trend occurred in specimens (A-15.9-10db-B/T), as a result of splitting cracks. 323 The ascending curve was similar for all specimens having the same surface configuration. 324 However, the descending curve varied with changing the failure mode. In addition, it was 325 noted that the shape of bond stress - slip curve of GFRP (type A) bar changes with 326 differing bar diameter. It may be attributed to the difference in the rib spacing with the bar 
diameter. While for the sand coated GFRP reinforced specimens, the bond failure was

328 relatively brittle and bond stress decayed abruptly to be almost zero accompanied with a

329 loud bang owing to stripping of sand coated layer. The post - peak bond stress starts 330 again to increase up to a certain value with increasing in the slip due to remaining frictional 331 resistance. This trend was observed for all hinged beams reinforced with GFRP (type B), 332 except two specimens (B-9.5-5d-B and B-12.7-5d-T), where their softening branches 333 reduced smoothly because of the partial detaching of sand coating. Also, the sudden 334 decrease in bond stress was noticed in hinged beam (B-15.9-10d-B) due to shear failure. 335 The residual stresses in GFRP (SC) reinforced hinged beams are lower than those in 336 GFRP (HW-SC) reinforced hinged beams because of the full detachment of sand coated 337 layer, leading to a smooth surface that was not able to provide with much frictional 338 resistance. The slip corresponding to the maximum bond stress obtained from GFRP 339 (type A) reinforced specimens is higher than that obtained from GFRP (type B) reinforced 340 specimens, indicating that the amount of slip is influenced by the surface treatment. The 341 effect of surface properties on the slip was also confirmed by Lee et al. [4] and Pepe et al. 342 [24]. All specimens reinforced with steel bars exhibited high initial stiffness without a slip 343 when chemical adhesion was dominated. Then, bond stress continued to increase with 344 very little slip until failure. At this stage, mechanical interlock and friction controlled to resist 345 the pull-out force. Unexpected failures occurred, the shear failure prior to the bond failure 346 in specimens having embedment length $5 \mathrm{db}$ and yielding happened before de-bonding, 347 following by shear crack in steel reinforced hinged beams having embedment length $10 \mathrm{db}$. 348 Which in turn results in abruptly dropping the value of bond stress as shown in Figure 6. 


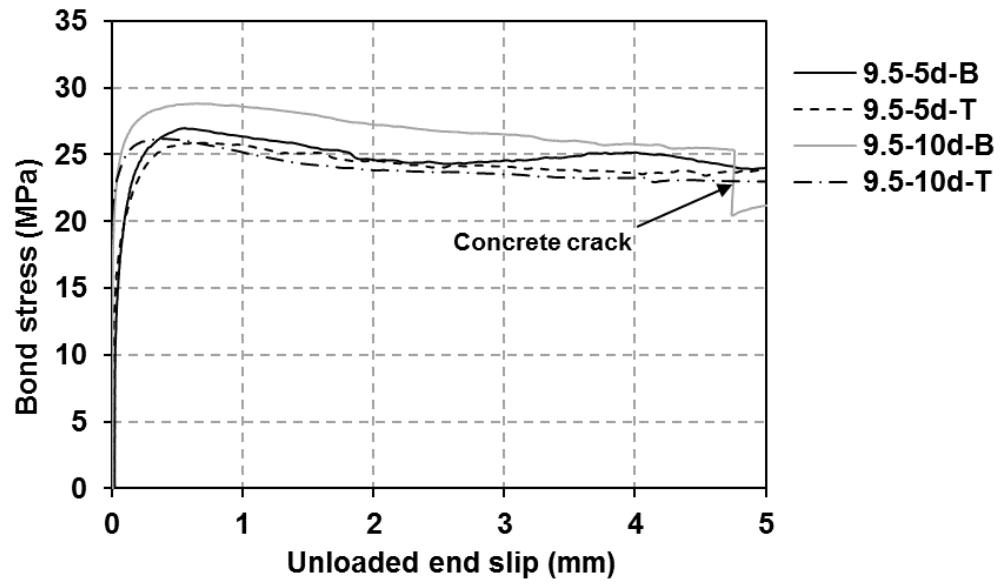

(a)

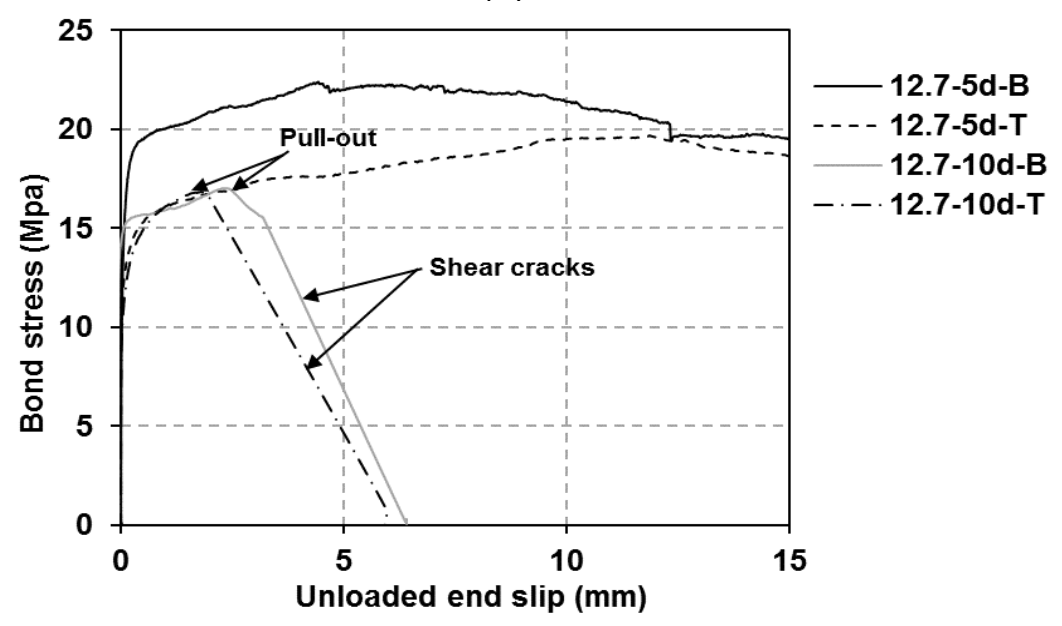

(b)

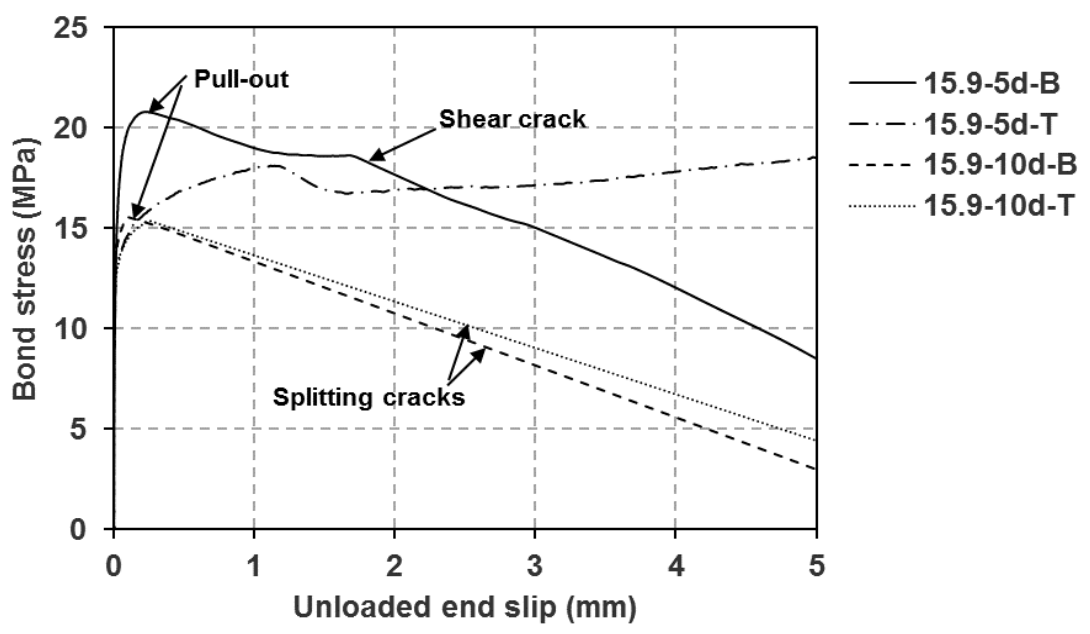

(c)

Figure 4. Bond stress versus free end slip for GFRP (HW-SC) bars 


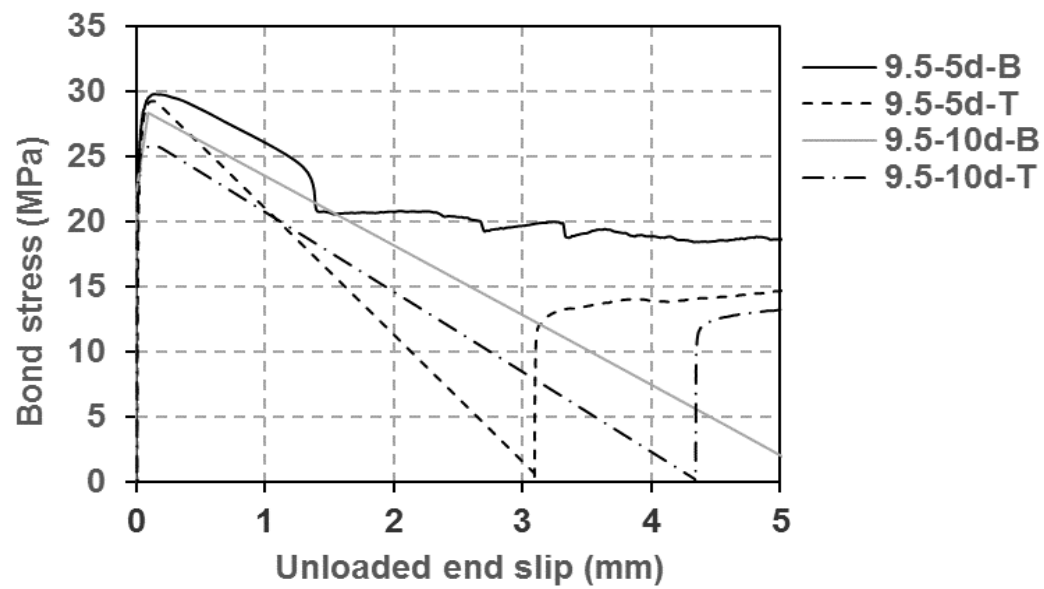

360

(a)

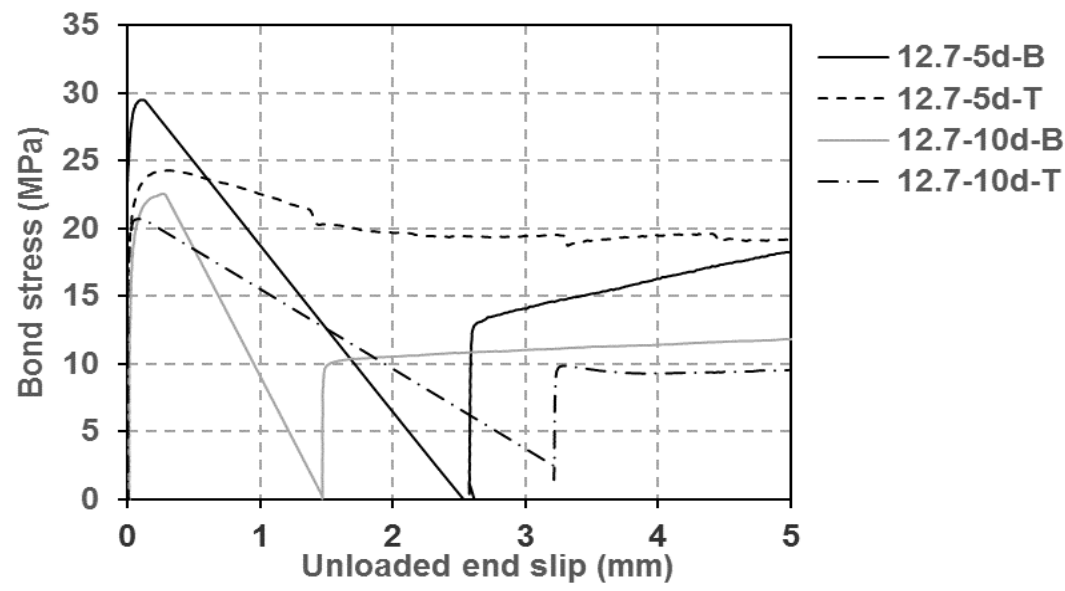

361

(b)

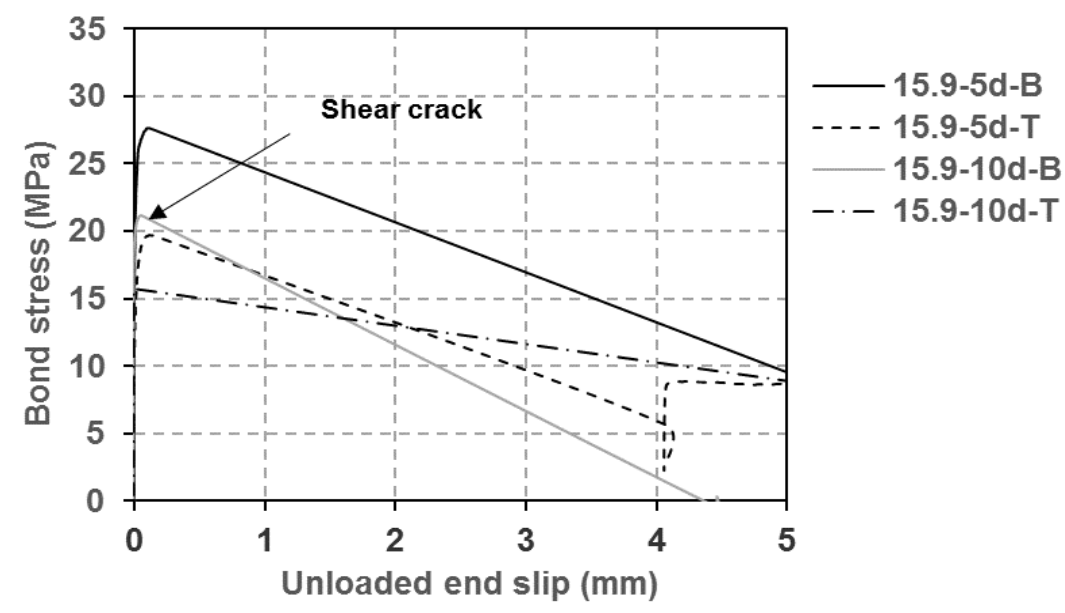

(c)

Figure 5. Bond stress versus free end slip for GFRP (SC) bars 


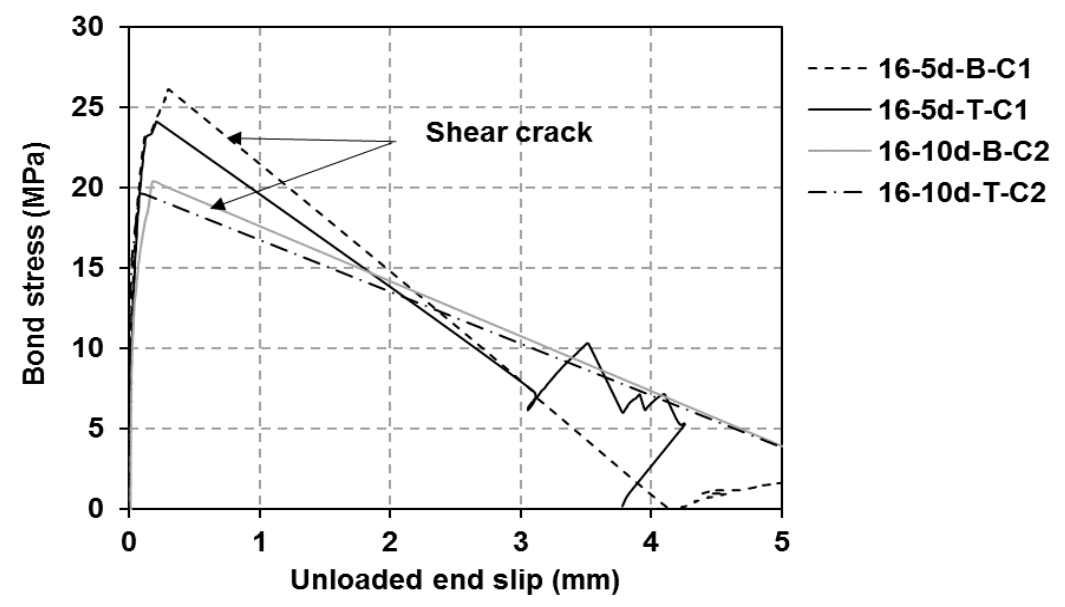

Figure 6. Bond stress versus free end slip for steel bars

370 The failure mode observed for each hinged beam is listed in Tables 2 and 3. Most

371 specimens failed by a pull-out mode as shown in Figures 7 (a) and 8 (a), except the

372 specimens reinforced with steel bars $(C-16-5 d-B / T)$ and specimen $(B-15.9-10 d-B)$ that

373 failed by shear cracks as illustrated in Figure 8 (b and c). For specimens (A-15.9-10d-

$374 \mathrm{~B} / \mathrm{T})$, pull-out failure accompanied with splitting cracks was observed as indicated in

375 Figure 7 (c). While the specimens $(A-12.7-10 d-B / T)$ and $(A-15.9-5 d-B)$ failed by a pull-out

376 mode followed by narrow diagonal cracks as shown in Figure 7 (b). Steel reinforced

377 hinged beams having embedment length $10 \mathrm{~d}_{\mathrm{b}}$ were failed by yielding subsequently shear

378 crack.

379 The specimens were split after testing to visually assess the bar and surrounding concrete 380 conditions. For helically wrapped with slightly sand coating GFRP reinforced specimens, 381 some abrasions were noted on the outer layer with stripping of sand coated layer as 382 described in Figure 9 (b). In addition, there was white residue on the trace of the whole 383 embedment length, indicating crushing of resin. However, the specimens with longer 384 embedment lengths failed by a damage of fibres as shown in Figure 9 (a). No apparent 
crushing of the surrounding concrete was monitored. As for specimens reinforced with sand coated GFRP bars, it was found that the concrete also remained uncrushed and concrete and sand coating.

390

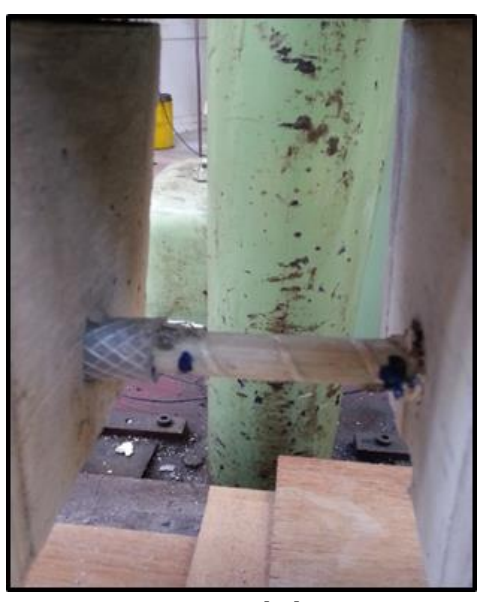

(a)

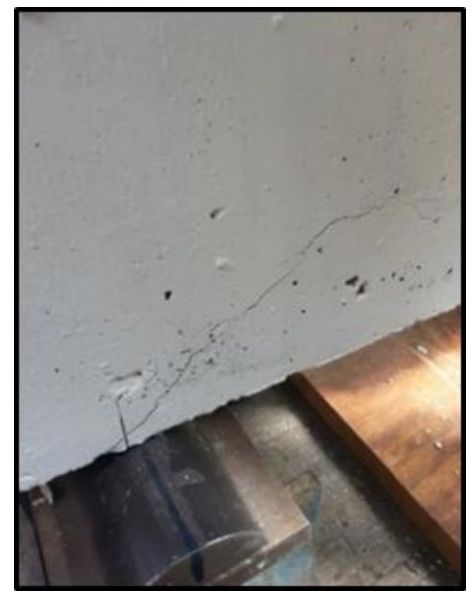

(b) 
402

403

404

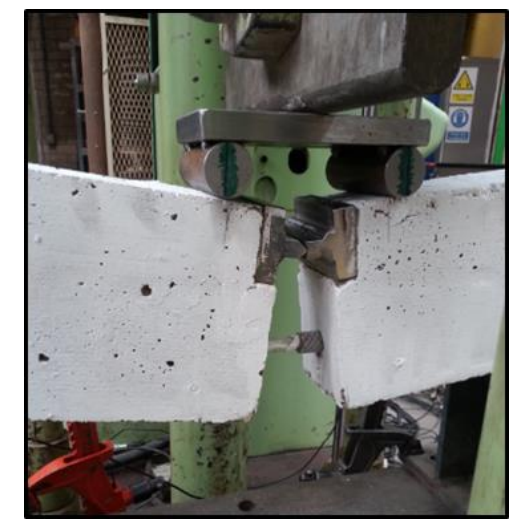

(a)

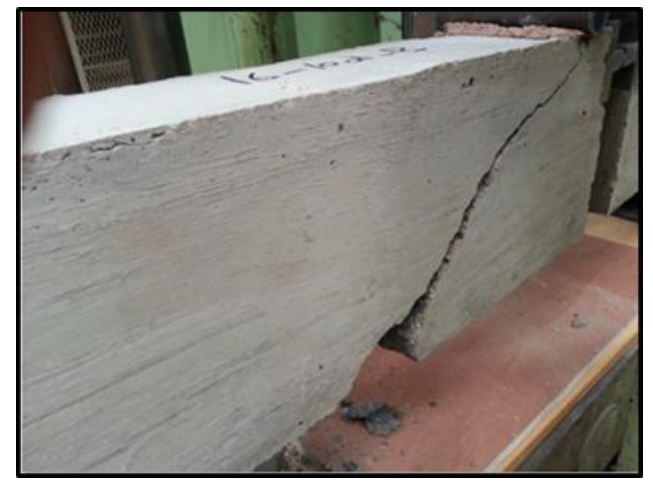

(b)

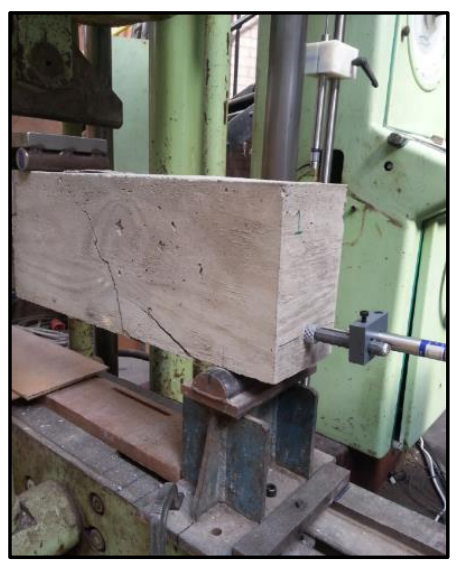

(c)

Figure 8. (a) Pull-out failure of GFRP (SC) reinforced specimen, (b) Shear crack in specimen (B-15.9-10d-B) and (c) Shear failure in steel reinforced specimen

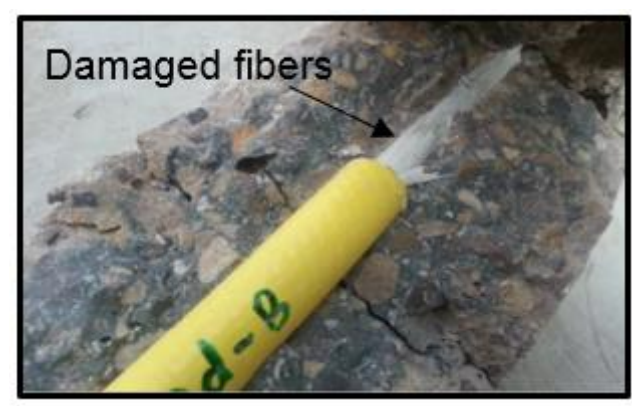

(a) Specimen (A-9.5-10d-B)

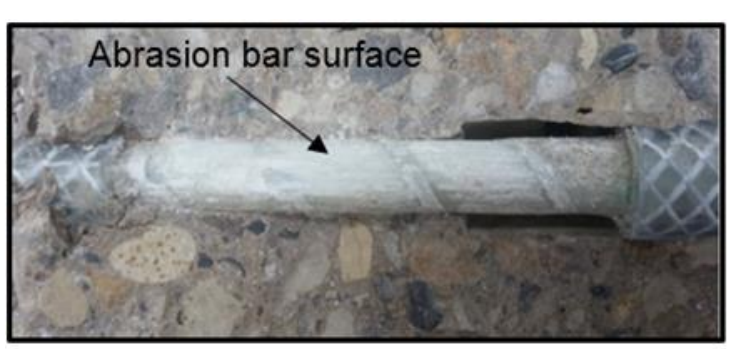

(b) Specimen (A-12.7-5d-B) 
434 the range of $5 \%$ to $24 \%$ and $12 \%$ to $20 \%$ for the bottom and top bar positions, respectively.

435 The bond strengths of sand coated and helically wrapped with slightly sand coated GFRP

436 bars measured in the current investigation are much higher than those observed in the 437 literature $[7,8]$ due to the high strength concrete of the current investigation and different

Figure 9. Visual inspection for the specimens failed by pull-out (images by author)

\subsection{Factors influencing bond strength}

\subsubsection{Effect of embedment length on bond strength}

In general, bond strength reduces with increasing bonded length as shown in Figures 10 and 11 because of non-linear distribution of bond stresses along the embedment length. This finding was confirmed by the results of Tighiouart et al. [8]. As the load increases, the bond stress at the vicinity of the unloaded end increases owing to the redistribution of shear stresses along the embedment length [7]. It is noticed that the reduction rate of bond strength of GFRP (HW-SC) reinforced specimens is approximately constant for all bar sizes, except for the $9.5 \mathrm{~mm}$ bar diameter. It is $24 \%$ and $15 \%$ for bottom and top bar positions, respectively. However, for GFRP (SC) reinforced specimens, the reduction rate of bond strength in smaller bar diameters is lower than that in larger bar diameters. It is in 438 surface configuration.

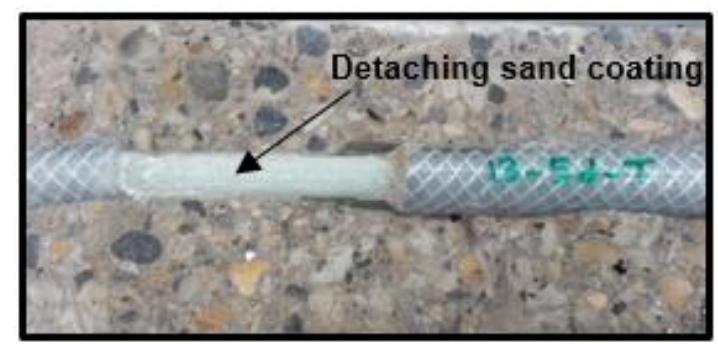

(c) Specimen (B-12.7-5d-T) 


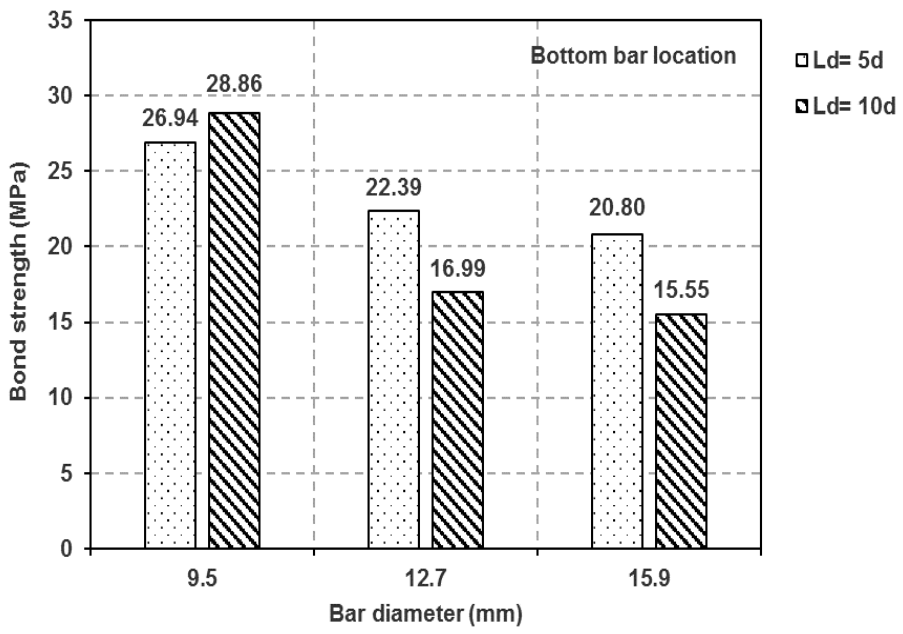

(a)

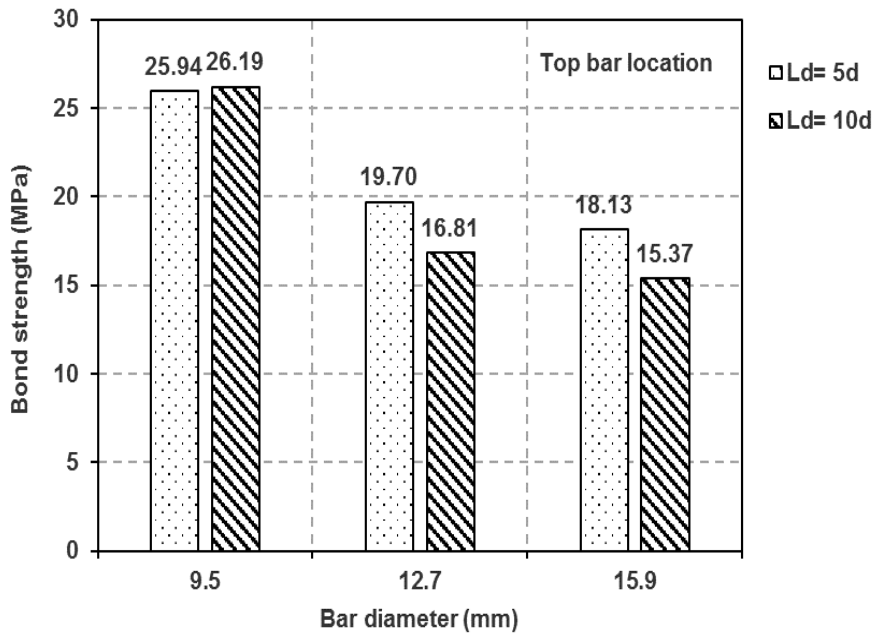

(b) strength of GFRP (HW-SC) bars (a) Bottom bar position and (b) Top bar position 


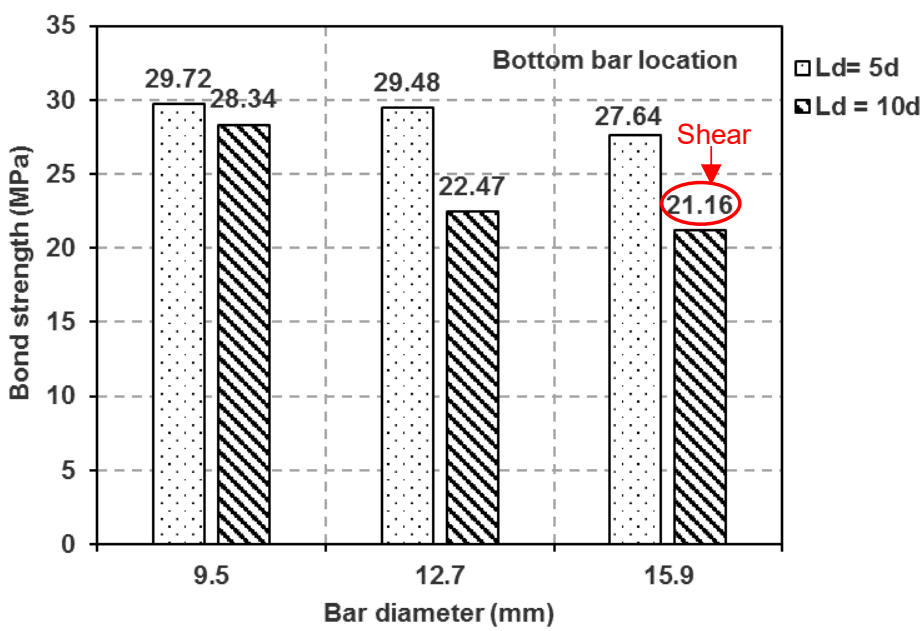

(a)

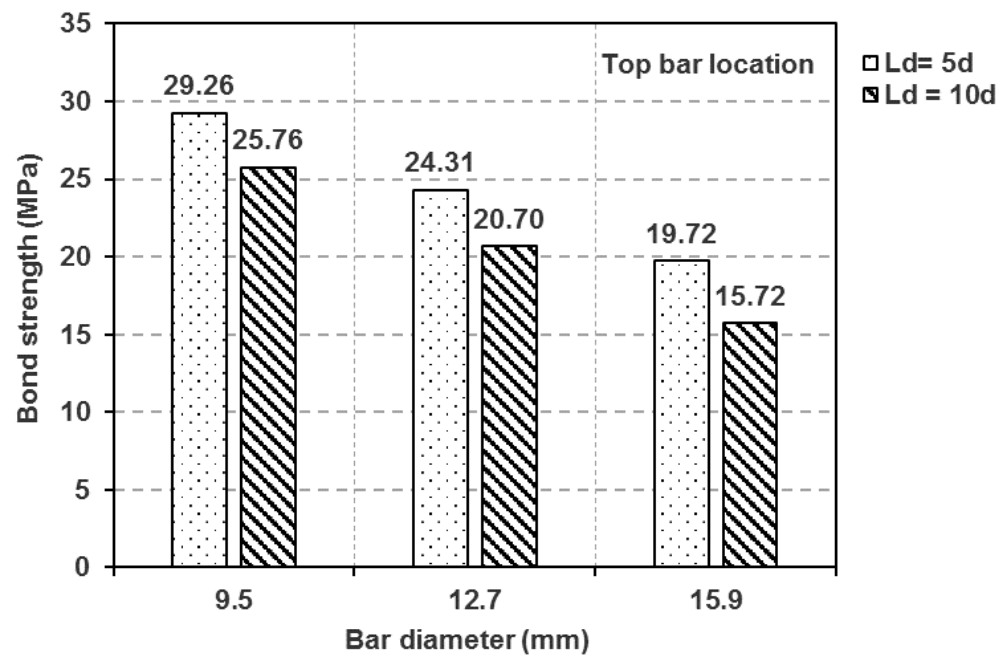

(b)

Figure 11. Effect of the embedment length and bar diameter on the average bond strength of GFRP (SC) bars (a) Bottom bar position and (b) Top bar position

\subsubsection{Effect of bar diameter on bond strength}

It can be seen from Figures 10 and 11 that the maximum bond strength increases for smaller bar diameters, agreeing with previous investigations on FRP and steel bars [2, 3,

$7,8,25]$. This phenomenon occurs due to bleeding of water underneath the bar, creating voids which in turn result in reducing the contact area between the bar and concrete [8]. The quantity of bleeding water trapped beneath larger bar diameters is greater than 
smaller ones. Therefore, the bond strength in larger bar diameters is lower than that in

464 smaller bar diameters. For high strength concrete, the reduction rate in bond strength

decreased with increasing bar diameter in GFRP (type A) reinforced specimens and

466 bottom casting specimens reinforced with GFRP (type B) bars. The same conclusion was

467 also reported by Lee et al. [5] for pull-out specimens. Whereas, a constant reduction rate

468 in bond strength was observed in specimens having GFRP (type B) top bars.

\subsubsection{Effect of bar position on bond strength}

471 Figures 12 and 13 show the distribution of ratios of the maximum bond strength of the 472 bottom bars to that of the top bars for both GFRP types. Top - cast bar specimens have 473 bond strengths slightly lower than those of bottom - cast bar specimens because of a little 474 bleeding water and a lower water / cement ratio, as reported by Pay et al. [15], Ferguson 475 and Thompson [26] and Jirsa et al. [27]. It was observed that an average reduction in 476 bond strength is $7 \%$ and 15\% for GFRP (Type A) and GFRP (Type B), respectively. The 477 most significant reduction (14\%) was measured in GFRP (HW-SC) reinforced specimens 478 having $12.7 \mathrm{~mm}$ and $15.9 \mathrm{~mm}$ bar diameters and $5 \mathrm{~d}_{\mathrm{b}}$ embedment length. As the bonded 479 length increased to $10 \mathrm{~d}_{\mathrm{b}}$, the ratio decreased leading to only a $1 \%$ strength reduction. 480 While, it is $17 \%$ and $28 \%$ for GFRP (SC) reinforced specimens with $12.7 \mathrm{~mm}$ and 15.9 $481 \mathrm{~mm}$ bar diameter, respectively, and $5 \mathrm{~d}_{\mathrm{b}}$ bonded length. This reduction in bond strength is 482 owing to bleeding water and segregation close to the top layers of concrete. Therefore, 483 the concrete surrounding the top bars is less consolidated compared to that surrounding 484 the bottom bars, a similar conclusion was obtained by Chaallal and Benmokrane [12], 485 Ehsani et. al [13], and Tighiouart et. al [8] from conducting the pull-out tests, and by Pay 486 et. al [15] from testing lap-splice beams. Based on the experimental work carried out 

herein, the top - casting specimens produced a minor reduction in bond strength. 488 Subsequently, these results obtained from top - casting specimens can be compared 489 directly with those obtained from bottom - bar specimens. In the worst case, they will be 490 slightly safe.

491

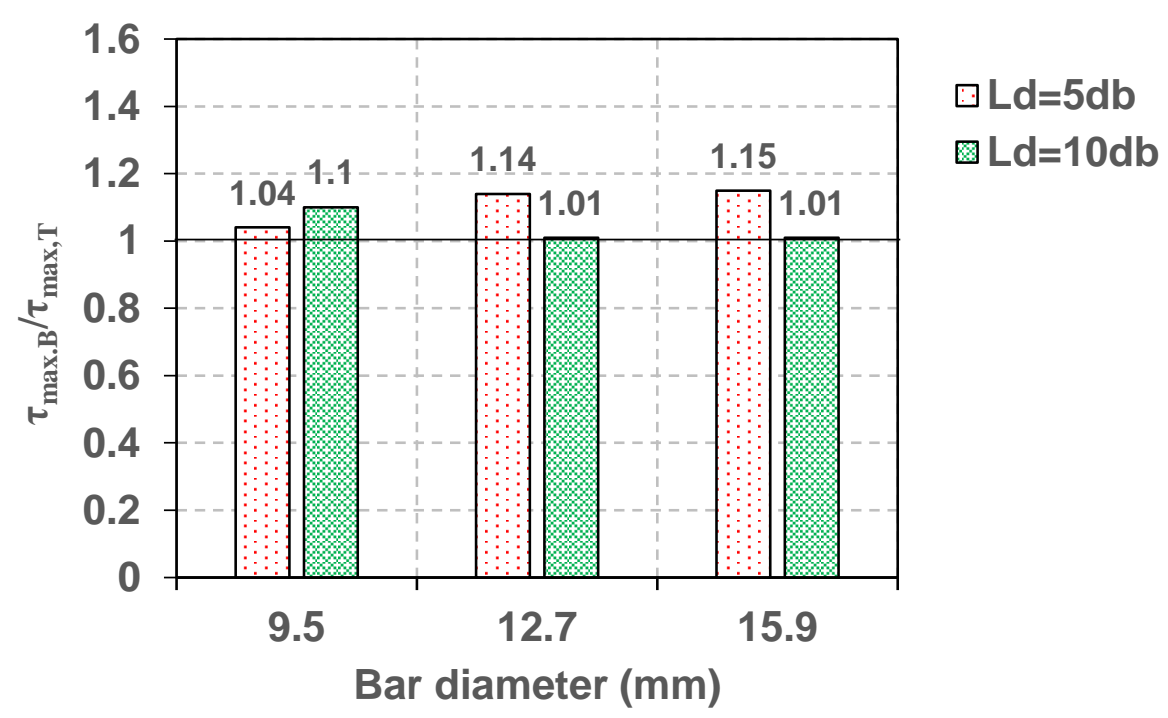

492

493

494

495

496
Figure 12. Comparison between bond strengths of GFRP (HW-SC) bottom bars and top bars

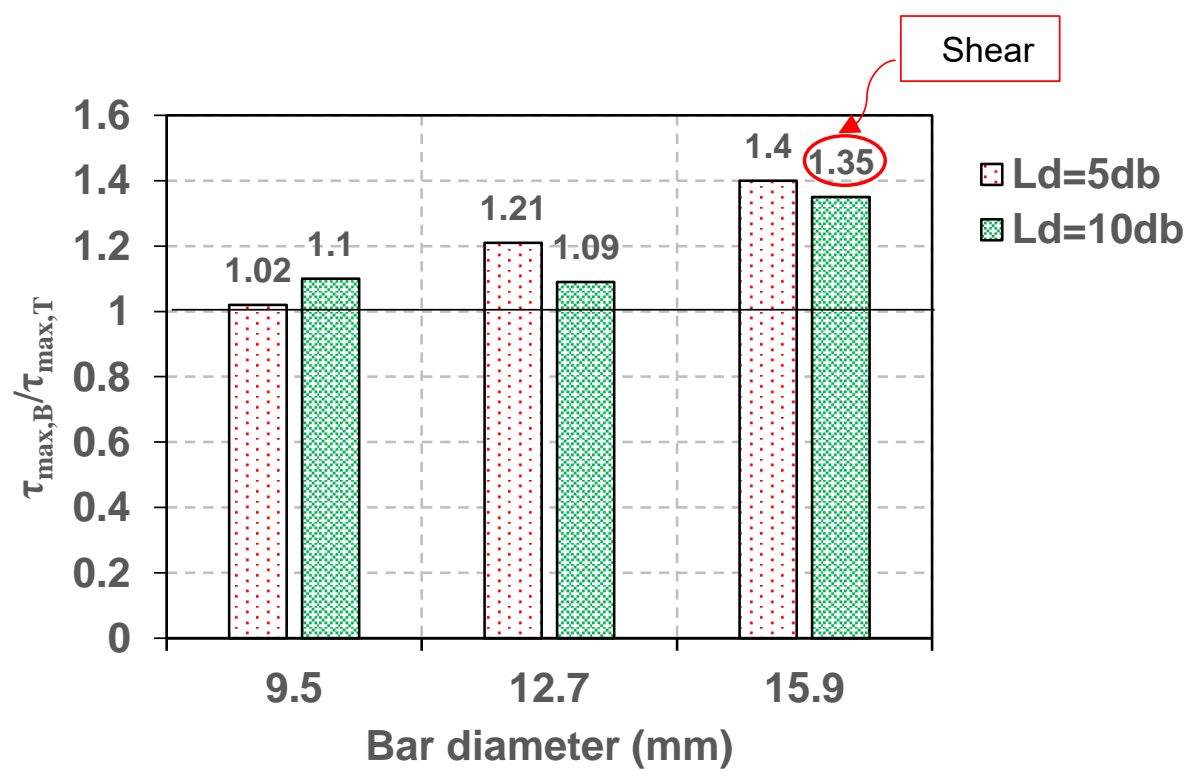

Figure 13. Comparison between bond strengths of GFRP (SC) bottom bars and top bars 


\subsubsection{Effect of bar surface on bond strength}

502 From Figures 14 and 15, it can be seen that the bond strength of GFRP (SC) bars is 503 higher than that of GFRP (HW-SC) bars owing to their sand coating surface. The ratio 504 varied from 1.1 to 1.36 and from 1.02 to 1.23 based on bar diameter and embedment 505 length for the bottom and top bars, respectively. However, the corresponding slip for 506 GFRP (SC) surface is smaller than that for GFRP (HW-SC) surface as demonstrated in 507 Tables 2 and 3 . It can be reported that sand coating improves the bond performance better 508 than helical wrapping as also reported by Cosenza et al. [28] and Davalos et al. [29]. 509 However, Lee et al. [4] found that the bond strength of GFRP (HW-SC) bars is higher than 510 that of GFRP (SC) bars for concrete strengths (25, 40 and $70 \mathrm{MPa})$ from testing pull-out 511 specimens.

512

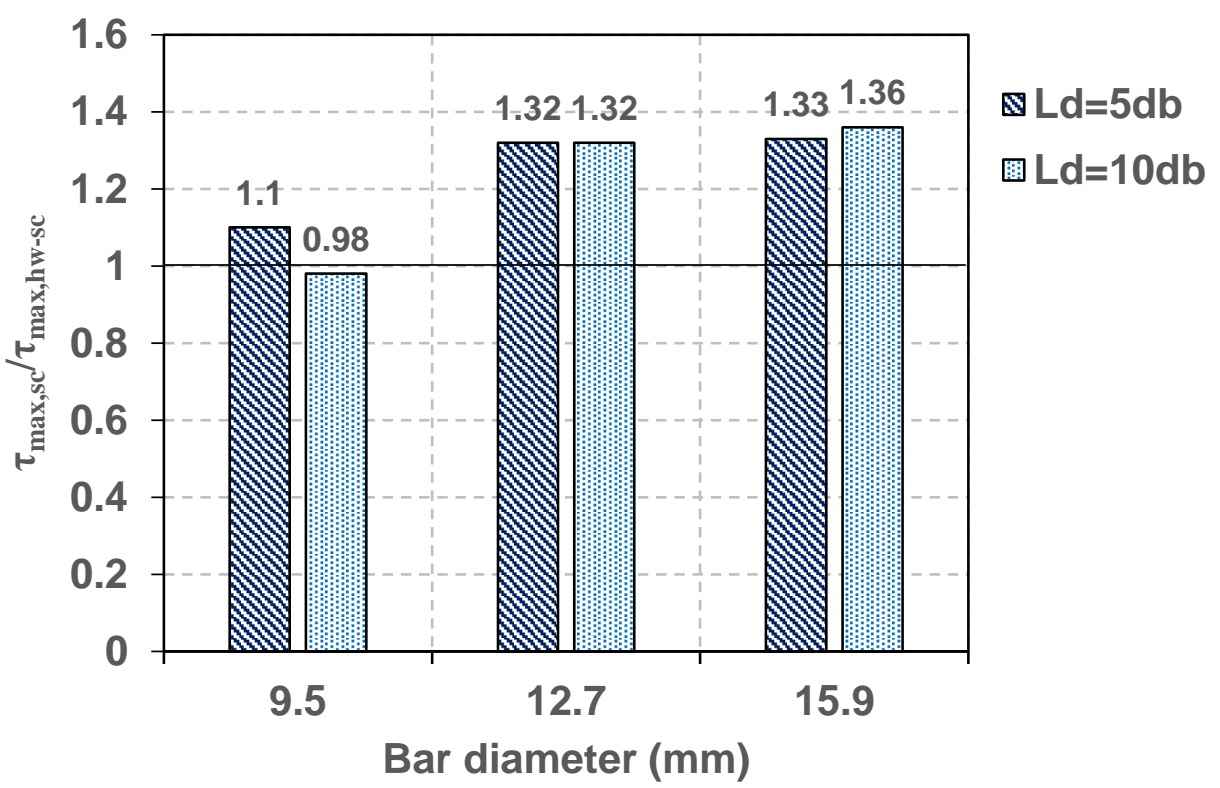

Figure 14. Comparison between bond strengths of GFRP (SC) and GFRP (HW-SC) surfaces for bottom bars 


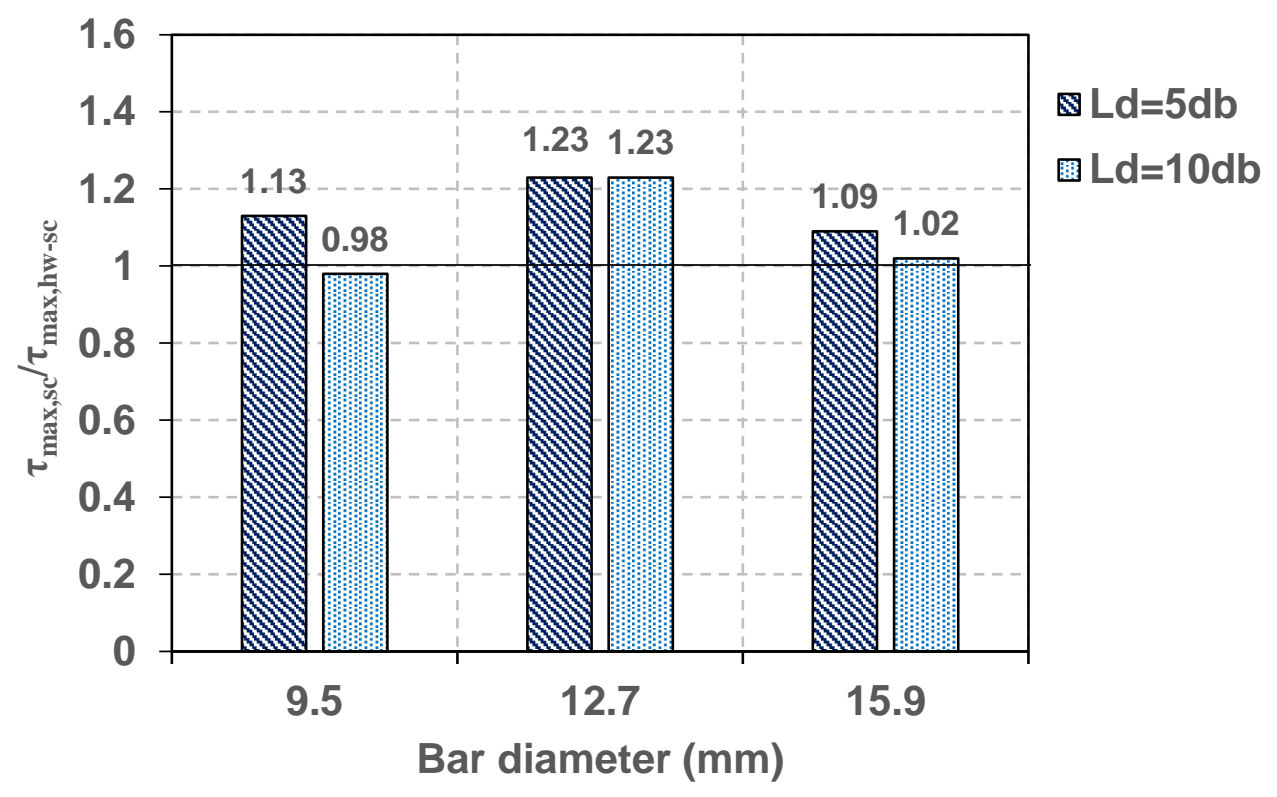

528

529

530

531

532

533 534 than 3.5. The CAN/CSA-S806 [17] and CAN/CSA-S6 [18] Canadian codes have also 535 proposed the expressions for estimating the development length of FRP bars in

Figure 15. Comparison between bond strengths of GFRP (SC) and GFRP (HW-SC) surfaces for top bars

\section{Comparison of test results with current codes}

For comparison purposes, the bond strengths provided by code equations were determined based on the geometrical and mechanical properties of the hinged beams. The ACI 440.1R [22] code has derived an equation for GFRP bars based on the work conducted by Wambeke and Shield [30] as shown below:

$$
\frac{\tau_{\max }}{0.083 \sqrt{\mathrm{f}_{\mathrm{c}}^{\prime}}}=4+0.3 \frac{\mathrm{c}}{\mathrm{d}_{\mathrm{b}}}+100 \frac{\mathrm{d}_{\mathrm{b}}}{\mathrm{l}_{\mathrm{e}}}
$$

where $\tau_{\max }$ is the bond strength (MPa), $\mathrm{f}_{\mathrm{c}}^{\prime}$ is the cylinder compressive strength of concrete $(\mathrm{MPa})$ and $\mathrm{c}$ is the lesser of the cover to the centre of the bar or one-half of the centre-tocentre spacing of the bars being developed $(\mathrm{mm})$. The ratio of $\mathrm{c} / \mathrm{d}_{\mathrm{b}}$ is limited to be less 
543 where:

where:

conventional concrete in order to avoid bond failure. These equations were substituted in equation 3 to produce the expressions 5 and 6 for CAN/CSA-S806 and CAN/CSA-S6, respectively, which are used to calculate bond strength.

$$
\tau_{\max }=\frac{\mathrm{d}_{\mathrm{cs}} \sqrt{\mathrm{f}_{\mathrm{c}}^{\prime}}}{1.15 \mathrm{k}_{1} \mathrm{k}_{2} \mathrm{k}_{3} \mathrm{k}_{4} \mathrm{k}_{5} \pi d_{b}}
$$

$$
\tau_{\max }=\frac{\left(\mathrm{d}_{\mathrm{cs}}+\mathrm{k}_{\mathrm{tr}} \frac{\mathrm{E}_{\mathrm{frp}}}{\mathrm{E}_{\mathrm{s}}}\right) \mathrm{f}_{\mathrm{cr}}}{0.45 \mathrm{k}_{1} \mathrm{k}_{6} \pi d_{b}}
$$

$$
k_{t r}=\frac{A_{t r} f_{y}}{10.5 s n} \quad \text { and } \quad\left(d_{c s}+k_{t r} \frac{E_{f r p}}{E_{s}}\right) \leq 2.5 d_{b}
$$

where $\mathbf{k}_{\mathbf{1}}$ is a bar location factor ( 1.3 for horizontal reinforcement placed so that more than $300 \mathrm{~mm}$ of fresh concrete is cast below the development length or splice, 1.0 for other cases), $\mathbf{k}_{2}$ is a concrete density factor (1.3 for structural low-density concrete, 1.2 for structural semi-low-density concrete, 1.0 for normal density concrete), $\mathbf{k}_{\mathbf{3}}$ is a bar size factor $\left(0.8\right.$ for $A_{b} \leq 300 \mathrm{~mm}^{2}, 1.0$ for $\left.A_{b}>300 \mathrm{~mm}^{2}\right), \quad \mathbf{A}_{\mathbf{b}}$ is the cross-sectional area of FRP bar $\left(\mathrm{mm}^{2}\right), \mathbf{k}_{\mathbf{4}}$ is a bar fibre factor ( 1.0 for GFRP), $\mathbf{k}_{\mathbf{5}}$ is a bar surface factor (1.0 for surface-roughened or sand-coated surfaces and 1.05 for spiral pattern surface), $\mathbf{k}_{6}$ is a bar surface factor, being the ratio of the bond strength of the FRP bar to that of a steel deformed bar with the same cross-sectional area as the FRP bar, but not greater than 1.0. In the absence of experimental data, $\mathrm{k}_{6}$ shall be taken as $0.8, \mathbf{d}_{\mathbf{c s}}$ is the smaller of the cover to the centre of the bar or two-thirds of the centre-to-centre spacing of the bars being developed $(\mathrm{mm})$ (not greater than $2.5 \mathrm{~d}_{\mathrm{b}}$ ), $\boldsymbol{k}_{\boldsymbol{t r}}$ is a transverse reinforcement index, $\boldsymbol{A}_{t r}$ is the cross-sectional area of transverse reinforcement $\left(\mathrm{mm}^{2}\right), \mathbf{s}$ is maximum spacing centre to centre of transverse bars within $l_{d}(\mathrm{~mm}), \boldsymbol{f}_{y t}$ is yield stress in transverse reinforcement (MPa), $\mathbf{n}$ is the number of bars being developed along the potential plane 
561 of bond splitting, $\boldsymbol{f}_{\boldsymbol{c}}$ is the cracking strength of concrete (MPa) $\left(0.4 \sqrt{f_{c}^{\prime}}\right.$ for normal-density 562 concrete, $0.34 \sqrt{f_{c}^{\prime}}$ for semi-low-density concrete, $0.3 \sqrt{f_{c}^{\prime}}$ for low-density concrete), $\mathbf{E}_{\text {frp }}$ 563 and $\mathbf{E}_{\mathbf{s}}$ are the modulus of elasticity of FRP and steel bars, respectively. The square root 564 of concrete strength should be less than 5 and $8 \mathrm{MPa}$ for CSA-S806 and CSA-S6, 565 respectively.

566

567

568

Tables 4 and 5 summarise the comparison of the experimental bond strength of various specimens and predictions using the methods provided in ACI 440.1R-15, CSA S806-12 and CSA S6-14. It can be seen that the ACI 440.1R code was more conservative for topcast GFRP reinforced specimens than bottom-cast GFRP reinforced ones. The CSA S806 and CSA S6 codes are too conservative, where the average ratios of experimental to predicted bond strengths are 5.33 and 3.1 with a COV of 24\% for GFRP (type A) bottom bars, respectively. Whereas, it is 4.95 and 2.88 with a COV of $23 \%$ for GFRP (type A) top bars, respectively. As for the GFRP (type B), the average ratios of experimental to predicted bond strengths are 6.37 and 3.89 with a COV of $11 \%$ for the bottom bars and 5.23 and 3.19 with a COV of $21 \%$ for the top bars. However, the average ratio of experimental to predicted bond strengths obtained from $\mathrm{ACl} 440$ code is 1.52 and 2.13 with a COV of $34 \%$ for the bottom and top GFRP (type A) bars, respectively. While it is 1.98 with a COV of $24 \%$ for the bottom GFRP (type B) bars and 2.55 with a COV of $28 \%$ for the top GFRP (type B) bars. Tables 4 and 5 showed that the bond strength obtained by Canadian codes is not influenced by bar diameter and embedment length. CSA-S806 code considers the bond strength of helically wrapped surface is less $(5 \%)$ than that of sand coating surface, while CSA-S6 recommended to use 0.8 for all surfaces, in absence the experimental data. Moreover, both Canadian codes neglect the effect of bar position 
on bond strength, as the depth of concrete underneath the bars is less than $300 \mathrm{~mm}$.

586 Therefore, there is no change in bond strength with changing bar position as illustrated in

587 Tables 4 and 5. The same observation was also confirmed by Hossain et al. [6]. In 588 contrast to the Canadian codes, the bond strength reduces with increasing embedment 589 length as per the $\mathrm{ACl} 440.1 \mathrm{R}$ code as shown in Figure 16 (a). In the $\mathrm{ACl} 440$ equation, 590 the effect of bar diameter on bond strength has been omitted by the normalized concrete 591 cover and embedment length. In addition, the ACI 440. 1R code ignores the influence of 592 surface configuration on bond strength. However, from tables 4 and 5 , there is a slight 593 increase in bond strength of GFRP (HW-SC) reinforced specimens compared to those 594 reinforced with GFRP (SC) bars, because of a small variation of concrete strength. It is 595 also noted from Figure 16 (a) that the predicted bond strength of the top bars is lower than 596 that of the bottom bars, because the $\mathrm{ACI} 440.1 \mathrm{R}$ code acknowledges the effect of bar 597 position by a modification factor 1.5. The ACI 440.1R equation was developed based on 598 concrete strength in the range of 28 to $45 \mathrm{MPa}$ [30]. Therefore, it cannot be assumed to 599 be accurate for predicting the bond strength of GFRP bar in HSC. The Canadian code 600 limitations regarding concrete strength and concrete cover lead to a constant value of 601 predicted bond strength for all test specimens as indicated in Figure 16 (b and c). Because 602 of the absence of transverse reinforcement in hinged beams, the effect of confinement 603 considered by transverse reinforcement index, $k_{t r}$, in the CSA S6 equation was neglected.

604 The minimum value of the bond strength in experimental results is higher than the bond 605 strengths obtained from Canadian design codes, thus, the development length provided 606 by these codes will be over satisfactory. 
Table 4. Comparison of test results of GFRP (type A) with different codes predictions

\begin{tabular}{|c|c|c|c|c|c|c|c|}
\hline $\begin{array}{c}\text { Specimen } \\
\text { label }\end{array}$ & $\begin{array}{c}\tau_{\text {exp }} \\
(\mathrm{MPa})\end{array}$ & $\begin{array}{c}\mathrm{ACl} \\
440.1 \mathrm{R} \\
\tau_{\text {pred }} \\
(\mathrm{MPa})\end{array}$ & $\frac{\tau_{\text {exp }}}{\tau_{\text {pred }}}$ & $\begin{array}{c}\text { CSA-S806 } \\
\tau_{\text {pred }} \\
\text { (MPa) }\end{array}$ & $\frac{\tau_{\text {exp }}}{\tau_{\text {pred }}}$ & $\begin{array}{c}\text { CSA-S6 } \\
\tau_{\text {pred }} \\
\text { (MPa) }\end{array}$ & $\frac{\tau_{\text {exp }}}{\tau_{\text {pred }}}$ \\
\hline$A-9.5-5 d-B$ & 26.94 & 18.23 & 1.42 & 4.11 & 6.55 & 7.07 & 3.81 \\
\hline$A-9.5-10 d-B$ & 28.86 & 10.95 & 2.54 & 4.11 & 7.02 & 7.07 & 4.08 \\
\hline$A-12.7-5 d-B$ & 22.39 & 18.23 & 1.18 & 4.11 & 5.45 & 7.07 & 3.17 \\
\hline$A-12.7-10 d-B$ & 16.99 & 10.95 & 1.49 & 4.11 & 4.13 & 7.07 & 2.40 \\
\hline$A-15.9-5 d-B$ & 20.80 & 18.16 & 1.10 & 4.11 & 5.06 & 7.07 & 2.94 \\
\hline$A-15.9-10 d-B$ & 15.55 & 10.88 & 1.38 & 4.11 & 3.78 & 7.07 & 2.20 \\
\hline \multicolumn{3}{|c|}{ Average } & 1.52 & & 5.33 & & 3.10 \\
\hline \multicolumn{3}{|c|}{ COV\% } & 34 & & 24 & & 24 \\
\hline$A-9.5-5 d-T$ & 25.94 & 12.16 & 2.06 & 4.11 & 6.31 & 7.07 & 3.67 \\
\hline A-9.5-10d-T & 26.19 & 7.30 & 3.46 & 4.11 & 6.37 & 7.07 & 3.70 \\
\hline$A-12.7-5 d-T$ & 19.70 & 12.16 & 1.56 & 4.11 & 4.79 & 7.07 & 2.79 \\
\hline A-12.7-10d-T & 16.81 & 7.30 & 2.22 & 4.11 & 4.09 & 7.07 & 2.38 \\
\hline A-15.9-5d-T & 18.13 & 12.10 & 1.44 & 4.11 & 4.41 & 7.07 & 2.56 \\
\hline A-15.9-10d-T & 15.37 & 7.25 & 2.04 & 4.11 & 3.74 & 7.07 & 2.17 \\
\hline C-16-5d-B & $>26.07$ & \multicolumn{6}{|c|}{$\mathrm{N} / \mathrm{A}$} \\
\hline C-16-5d-T & $>24.06$ & \multicolumn{6}{|c|}{$\mathrm{N} / \mathrm{A}$} \\
\hline \multicolumn{3}{|c|}{ Average } & 2.13 & & 4.95 & & 2.88 \\
\hline \multicolumn{3}{|c|}{ COV\% } & 34 & & 23 & & 23 \\
\hline
\end{tabular}
a Coefficient of variation and N/A = Not applicable. 
631

632

Table 5. Comparison of test results of GFRP (type B) with different codes predictions

\begin{tabular}{|c|c|c|c|c|c|c|c|}
\hline $\begin{array}{c}\text { Specimen } \\
\text { label }\end{array}$ & $\begin{array}{c}\tau_{\text {exp }} \\
(\mathrm{MPa})\end{array}$ & $\begin{array}{c}\mathrm{ACl} \\
440.1 \mathrm{R} \\
\tau_{\text {pred }} \\
(\mathrm{MPa})\end{array}$ & $\frac{\tau_{\text {exp }}}{\tau_{\text {pred }}}$ & $\begin{array}{c}\text { CSA-S806 } \\
\tau_{\text {pred }} \\
\text { (MPa) }\end{array}$ & $\frac{\tau_{\text {exp }}}{\tau_{\text {pred }}}$ & $\begin{array}{c}\text { CSA-S6 } \\
\tau_{\text {pred }} \\
\text { (MPa) }\end{array}$ & $\frac{\tau_{\text {exp }}}{\tau_{\text {pred }}}$ \\
\hline B-9.5-5d-B & 29.72 & 17.33 & 1.71 & 4.32 & 6.88 & 7.07 & 4.20 \\
\hline B-9.5-10d-B & 28.34 & 10.41 & 2.72 & 4.32 & 6.56 & 7.07 & 4.01 \\
\hline B-12.7-5d-B & 29.48 & 17.33 & 1.70 & 4.32 & 6.82 & 7.07 & 4.17 \\
\hline B-12.7-10d-B & 22.47 & 10.41 & 2.16 & 4.32 & 5.20 & 7.07 & 3.18 \\
\hline B-15.9-5d-B & 27.64 & 17.26 & 1.60 & 4.32 & 6.40 & 7.07 & 3.91 \\
\hline B-15.9-10d-B & $>21.16$ & 10.34 & $\mathrm{~N} / \mathrm{A}$ & 4.32 & $\mathrm{~N} / \mathrm{A}$ & 7.07 & $\mathrm{~N} / \mathrm{A}$ \\
\hline \multicolumn{3}{|c|}{ Average } & 1.98 & & 6.37 & & 3.89 \\
\hline \multicolumn{3}{|c|}{ COV\% } & 24 & & 11 & & 11 \\
\hline B-9.5-5d-T & 29.26 & 11.55 & 2.53 & 4.32 & 6.77 & 7.07 & 4.14 \\
\hline B-9.5-10d-T & 25.76 & 6.94 & 3.71 & 4.32 & 5.96 & 7.07 & 3.64 \\
\hline B-12.7-5d-T & 24.31 & 11.55 & 2.10 & 4.32 & 5.63 & 7.07 & 3.44 \\
\hline B-12.7-10d-T & 20.70 & 6.94 & 2.98 & 4.32 & 4.79 & 7.07 & 2.93 \\
\hline B-15.9-5d-T & 19.72 & 11.50 & 1.71 & 4.32 & 4.56 & 7.07 & 2.79 \\
\hline B-15.9-10d-T & 15.72 & 6.89 & 2.28 & 4.32 & 3.64 & 7.07 & 2.22 \\
\hline C-16-10d-B & $>20.37$ & \multicolumn{6}{|c|}{$\mathrm{N} / \mathrm{A}$} \\
\hline C-16-10d-T & $>19.65$ & \multicolumn{6}{|c|}{$\mathrm{N} / \mathrm{A}$} \\
\hline \multicolumn{3}{|c|}{ Average } & 2.55 & & 5.23 & & 3.19 \\
\hline \multicolumn{3}{|c|}{ COV\% } & 28 & & 21 & & 21 \\
\hline
\end{tabular}

633

Note: $\tau_{\exp }$ is the experimental bond strength; $\tau_{\text {pred }}$ is the predicted bond strength; COV is a Coefficient of variation and $\mathrm{N} / \mathrm{A}=$ Not applicable.

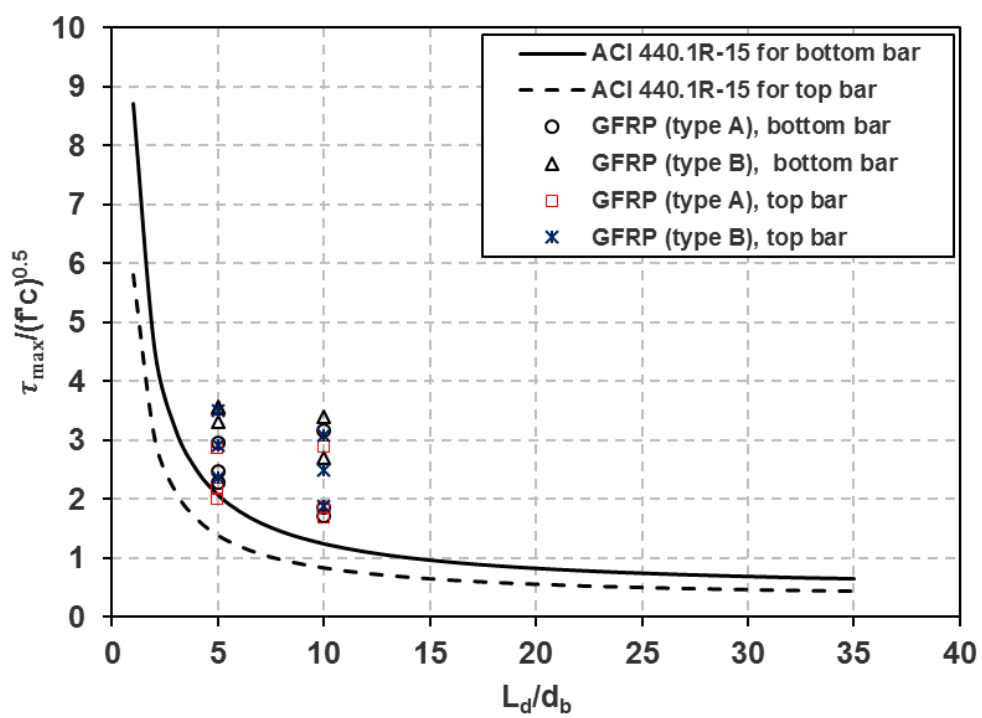

(a) Variation of maximum bond stress with embedment length 


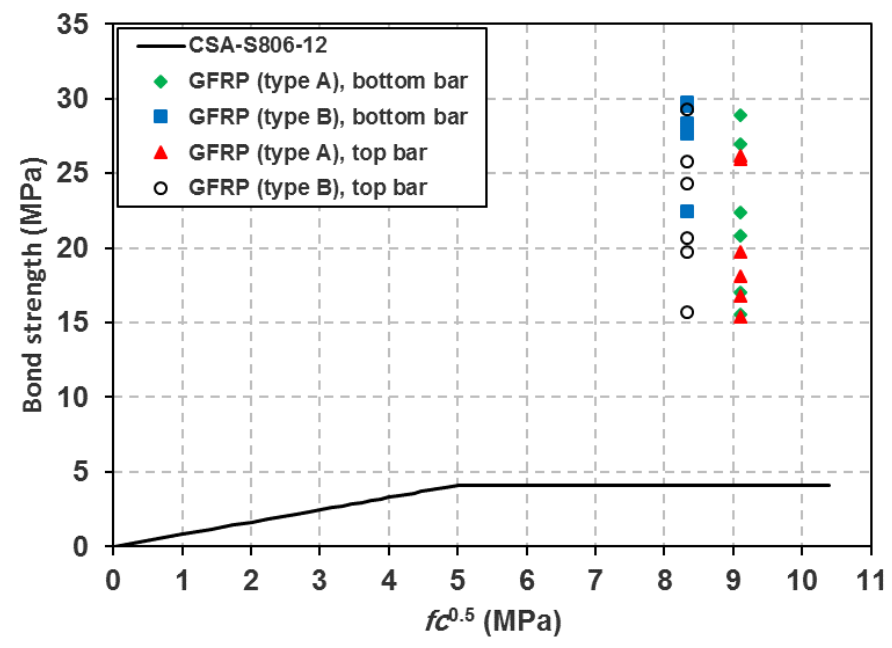

(b) Bond strength vs. square root of concrete strength

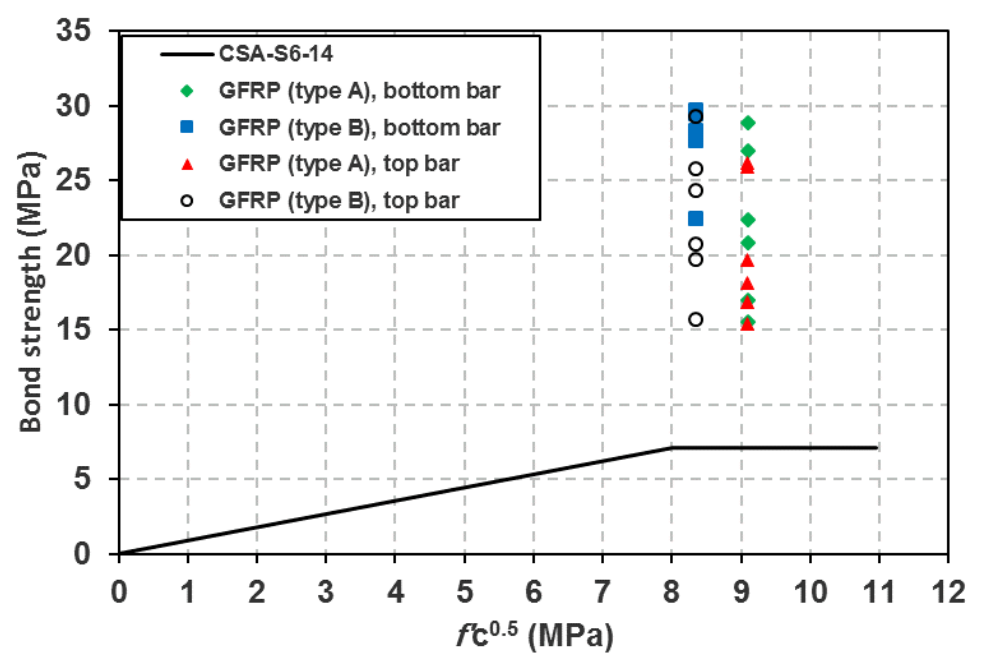

(c) Bond strength vs. square root of concrete strength

\section{Figure 16. Comparison between predicted and experimental bond strengths}

\section{Conclusions}

648 Test results of 28 HSC hinged beams reinforced with GFRP and steel bars have been

649 presented and discussed in this paper. The parameters investigated were diameter, 650 embedment length, surface configuration and position of reinforcing bars. The following 651 conclusions are drawn: 


\section{2}

673

674

1. Pull-out failure was observed in most specimens. Bond failure was governed by damage of the outer layer of GFRP (HW-SC) bars, while it was due to detachment of sand grains on the GFRP (SC) surface.

2. In the case of high strength concrete, after the peak bond stress, the GFRP (HWSC) bars showed a gradual reduction in bond stresses due to friction resistance, whereas the GFRP (SC) bars showed sudden bond failure with complete loss of bond resistance because of stripping of the sand grains.

3. The bond strength of GFRP (SC) bars is higher than that of GFRP (HW-SC) bars. However, the corresponding slip for GFRP (SC) bars is less than that for GFRP (HW-SC) bars.

4. Bond strength reduces with increasing embedment length and bar diameter. For high strength concrete, the reduction rate in bond strength decreased with increasing bar size in all specimens, except top-cast specimens reinforced with GFRP (SC) bars having a constant reduction rate.

5. Top-cast specimens exhibited slightly lower bond strengths (average $7 \%$ and $15 \%$ reduction for GFRP (HW-SC) and GFRP (SC), respectively) than bottom-cast specimens.

6. CSA-S806 and CSA-S6 codes provide more conservative predictions of bond strengths of GFRP (HW-SC) and GFRP (SC) bars in high strength concrete than those provided by $\mathrm{ACl} 440.1 \mathrm{R}$ code

\section{Acknowledgement}

Authors would like to express their great appreciation and gratefully acknowledge to Ministry of Higher Education in Libya for funding this research work. 


\section{References}

1. Achillides, Z. and K. Pilakoutas, Bond behavior of fiber reinforced polymer bars under direct pullout conditions. Journal of Composites for Construction, 2004. 8(2): p. 173-181.

2. Okelo, R. and R.L. Yuan, Bond strength of fiber reinforced polymer rebars in normal strength concrete. Journal of composites for construction, 2005. 9(3): p. 203-213.

3. Baena, M., et al., Experimental study of bond behaviour between concrete and FRP bars using a pull-out test. Composites Part B: Engineering, 2009. 40(8): p. 784-797.

4. Lee, J.Y., et al., Bond stress-slip behaviour of two common GFRP rebar types with pullout failure. Magazine of Concrete Research, 2012. 64(7): p. 575-591.

5. Lee, J.-Y., et al., Bond behaviour of GFRP bars in high-strength concrete: bar diameter effect. Magazine of Concrete Research, 2017. 69(11): p. 541-554.

6. Hossain, K.M.A., D. Ametrano, and M. Lachemi, Bond Strength of Standard and High-Modulus GFRP Bars in High-Strength Concrete. Journal of Materials in Civil Engineering, 2014. 26(3): p. 449-456.

7. Benmokrane, B., B. Tighiouart, and O. Chaallal, Bond strength and load distribution of composite GFRP reinforcing bars in concrete. ACI Materials Journal, 1996. 93(3): p. 246-252.

8. Tighiouart, B., B. Benmokrane, and D. Gao, Investigation of bond in concrete member with fibre reinforced polymer (FRP) bars. Construction and Building Materials, 1998. 12(8): p. 453-462.

9. Ovitigala, T. and M. Issa, Mechanical and Bond Strength of Basalt Fiber Reinforced Polymer (BFRP) Bars for Concrete Structures, in Proceedings of the 11th International Symposium on FRP for Reinforced Concrete Structures. Guimaraes, Portugal. 2013.

10. Xue, W., et al., Bond behavior of sand-coated deformed glass fiber reinforced polymer rebars. Journal of Reinforced Plastics and Composites, 2014. 33(10): p. 895-910.

11. Mazaheripour, H., et al., Experimental study on bond performance of GFRP bars in self-compacting steel fiber reinforced concrete. Composite Structures, 2013. 95: p. 202-212.

12. Chaallal, O. and B. Benmokrane, Pullout and bond of glass-fibre rods embedded in concrete and cement grout. Materials and structures, 1993. 26(3): p. 167-175.

13. Ehsani, M.R., H. Saadatmanesh, and S. Tao. Bond Behaviour and Design Recommendations for Fiberglass Reinforcing Bars. in Proceeding of the first International Conference on Composites in Infrastructure (ICCI-96). 1996b. Tucson, Ariz.

14. Benmokrane, B. and R. Masmoudi. FRP C-bar as reinforcing rod for concrete structures. in PROCEEDINGS OF THE 2ND INTERNATIONAL CONFERENCE ON ADVANCED COMPOSITE MATERIALS IN BRIDGES AND STRUCTURES, ACMBS-II, MONTREAL. 1996.

15. Pay, A.C., E. Canbay, and R.J. Frosch, Bond strength of spliced fiber-reinforced polymer reinforcement. ACI Structural Journal, 2014. 111(2): p. 257-266. 
16. Golafshani, E.M., A. Rahai, and M.H. Sebt, Bond behavior of steel and GFRP bars in self-compacting concrete. Construction and Building Materials, 2014. 61: p. 230240.

17. CAN/CSA-S806, Design and construction of building structures with fibrereinforced polymers. 2012, Canadian Standards Association: Mississauga, Ontario, Canada.

18. CAN/CSA-S6, Canadian Highway Bridge Design Code. 2014, Canadian Standard Association.

19. ASTM-D7205/D7205M-06, Standard test method for tensile properties of fibre reinforced polymer matrix composite bars. 2006, ASTM International: West Conshohocken, United States. p. 13.

20. ASTM-A706/A706M-09b, Standard Specification for Low-Alloy Steel Deformed and Plain Bars for Concrete Reinforcement. 2009, ASTM International: West Conshohocken, United States. p. 6.

21. ACl-440.3R, Guide Test Methods for Fiber-Reinforced Polymers (FRPs) for Reinforcing or Strengthening Concrete Structures. 2012, ACl Committee 440: Farmington Hills, M1.

22. ACl-440.1R, Guide for the design and construction of concrete reinforced with FRP bars. 2015, ACl Committee 440: Farmington Hills, M1.

23. RILEM/CEB/FIP, R., RILEM technical recommendations for the testing and use of construction materials 1982, London : Spon, c1994. p. 213-217.

24. Pepe, M., et al., Numerical calibration of bond law for GFRP bars embedded in steel fibre-reinforced self-compacting concrete. Composites Part B: Engineering, 2013. 50: p. 403-412.

25. Achillides, Z., Bond behaviour of FRP bars in concrete, in Dept. of Civil and Structural Engineering. 1998, University of Sheffield: Sheffield, U.K.

26. Ferguson, P.M. and J.N. Thompson, Development Length of High Strength Reinforcing Bars in Bond. ACl Journal, 1962. 59(7): p. 887-922.

27. Jirsa, J.O., et al. Effect of casting position on bond. in International Conference on Bond in Concrete. 1982. Paisley College of Technology, Paisley, Scotland.

28. Cosenza, E., G. Manfredi, and R. Realfonzo, Behavior and modeling of bond of FRP rebars to concrete. Journal of composites for construction, 1997. 1(2): p. 4051.

29. Davalos, J.F., Y. Chen, and I. Ray, Effect of FRP bar degradation on interface bond with high strength concrete. Cement and Concrete Composites, 2008. 30(8): p. 722-730.

30. Wambeke, B.W. and C.K. Shield, Development length of glass fiber-reinforced polymer bars in concrete. ACI Structural Journal, 2006. 103(1): p. 11-17. 